\title{
TERMINATION OF AFFERENT AXONS IN MACAQUE STRIATE CORTEX $^{1}$
}

\author{
GARY G. BLASDEL ${ }^{2}$ AND JENNIFER S. LUND \\ Departments of Anatomy and Ophthalmology, Medical University of South Carolina, Charleston, South Carolina 29425
}

Received September 13, 1982; Revised January 12, 1983; Accepted January 14, 1983

\begin{abstract}
We used horseradish peroxidase (HRP) to orthogradely label afferent axons in macaque striate cortex. Of the 38 axons that we recovered, nine were recorded intracellularly before being filled with HRP. Light microscope and computer reconstructions of filled processes reveal highly stereotyped patterns of arborization and suggest that there are at least five discrete populations of lateral geniculate nucleus (LGN) afferent axon: (1) those to layer $4 \mathrm{C} \beta$, which have extremely circumscribed, dense terminal fields (small branches of which occasionally intrude into $4 \mathrm{C} \alpha$ ) but which have not been shown to project to other laminae; (2) afferents to layer $4 \mathrm{~A}$, which in some cases send fine ascending collaterals into layer 2-3 and which do not, apparently, send collaterals to other laminae; (3) afferents to layer 1, which are fine, extend over large distances horizontally, and send collaterals to layer $6 \mathrm{~A}$; (4) afferents to the lower two-thirds of layer $4 \mathrm{C} \alpha$, which have few or no collaterals in layer 6; and (5) afferents to the upper half of layer $4 \mathrm{C} \alpha$, which have arborizing collaterals in layer $6 \mathrm{~B}$. Of the nine axons that were recorded intracellularly, those with projections to layer $4 \mathrm{C} \beta$ (two axons) and to layer 1 (one axon) had color-selective properties, whereas those (six axons) which arborized in $4 \mathrm{C} \alpha$ all had transient, broad band and highly contrast-sensitive receptive fields. These properties are consistent with derivations from somata in the parvocellular and magnocellular divisions of the LGN, respectively. Afferents to $4 \mathrm{C} \alpha$ were found to cover approximately 6 times as much surface area as afferents to $4 \mathrm{C} \beta$. The preterminal trunks of all axons were found to follow tortuous paths through the neuropil-paths that may derive from axon segregation during development. The wide ranging, patchy distributions of single afferents in $4 \mathrm{C} \alpha$ suggest that individual $4 \mathrm{C} \alpha$ axons supply more than one ocular dominance stripe. In one case where the terminal arborization of a $4 \mathrm{C} \alpha$ axon was mapped against the transneuronally determined pattern of ocular dominance, three separate patches of terminal boutons were indeed found to coincide with the bands of one eye.
\end{abstract}

The primate visual system is characterized by successive and discrete transformations in the neural representation of visual space. One such transformation occurs between the lateral geniculate nucleus (LGN) and cells in the thalamo-recipient laminae of striate cortex. Even though the receptive fields of cells in layer 4C-the layer that receives most of the LGN input-lack orientation selectivity and to some extent resemble those of the LGN, the transfer of information seems not to occur in

\footnotetext{
${ }^{1}$ This research was supported by National Eye Institute Grants EY03321 and EY-04064, and by the South Carolina State Appropriated Fund. We thank Drs. David Hubel, David Van Essen, Horace Barlow, Jack Pelligrew, David Fitzpatrick, and Kathleen Rockland who commented on the manuscript and Tony Movshon for helpful discussion. We are also grateful to Kathryn Cowart, who performed most of the histology and helped with photography and illustrations, David Whitaker, who provided technical assistance, and Diane Ashworth, who typed the manuscript.

${ }^{2}$ To whom correspondence should be addressed.
}

a simple one-to-one fashion. As with most other pathways in the mammalian nervous system, there is divergence and convergence. Divergence is obvious from the fact that there are more cells in layer $4 \mathrm{C}-100$ times more according to some estimates (Chow et al., 1950)than there are in the LGN. Convergence, on the other hand, is implied by the finding that those cortical cells most strongly resembling LGN neurons, the nonoriented ones found in layer $4 \mathrm{C}$, combine response properties such as color opponency that occur only separately in single cells of the I.GN (Hubel and Wiesel, 1968; Gouras, 1974; Michael, 1978). The transfer of visual information from the LGN to striate cortex, therefore, entails some degree of rearrangement; and it would appear reasonable to expect that the transformation that occurs-one characterized by divergence and convergence-bears some relation to the ways in which single LGN afferents make contact with the postsynaptic cortical cells.

For the macaque monkey the terminations of LGN 
afferents are characterized by a highly ordered and parcellated arrangement. Segregation may be seen both vertically, between pia and white matter, and horizontally, in the plane of the cortical surface. In the vertical domain, afferents from different LGN laminae terminate in discrete cortical layers. Whereas afferents from the magnocellular laminae reportedly confine themselves to $4 \mathrm{C} \alpha$ and the lower part of layer 6, afferents from the parvocellular LGN laminae project strongly to layers $4 \mathrm{~A}$ and $4 \mathrm{C} \beta$ and probably to layers 1 and 6 as well (Hubel and Wiesel, 1972; Hendrickson et al., 1978). Recent work (Hubel and Livingston, 1981; Fitzpatrick et al., 1983) has indicated an additional projection from the intercalated LGN laminae to discrete patches in layer 3 . In the horizontal domain, Hubel and Wiesel have shown (1972, 1977), using a number of different techniques, that $4 \mathrm{C}$ afferents from LGN laminae corresponding to the two eyes terminate in a side-by-side arrangement of interdigitating bands-each about $400 \mu \mathrm{m}$ wide-that are thought to form the structural basis of ocular dominance "columns." Postsynaptically, and also in the horizontal domain, one sees an cven finer arrangement in the receptive field positions of $4 \mathrm{C}$ cells-positions which have been shown (Hubel et al., 1974) to shift in a strict retinotopic fashion for displacements that are tangential to the cortical surface. The resulting retinotopic map, which might be presumed to derive from a further parcellation of afferent fibers, can be seen physiologically even within the width of a single ocular dominance column; that is, within about $400 \mu \mathrm{m}$.

Explanations of the observed parcellation are as yet unknown. In spite of the numerous neurophysiological and neuroanatomical experiments that have been performed on this pathway to date, the precise manner in which single LGN afferents distribute their terminals in the monkey remains to be explored. Axons suggested to be thalamic projections to layer $4 \mathrm{C}$ have been described from Golgi-impregnated tissue (Valverde, 1971; Lund, 1973), but these descriptions provide little information about the overall spread of individual fibers and the axons themselves may not be from the LGN. Most recently, Ferster and LeVay (1978) studied the terminations of individual afferents in cat striate cortex by orthogradely filling cut axons of the optic radiation with horseradish peroxidase (HRP). The identification of these fibers, as LGN afferents, has since been established by the intracellular recordings and HRP injections of Gilbert and Wiesel (1979). The observed afferents to thalamorecipient laminae were found to arborize frequently in more than one lamina and to spread over surprisingly large areas of striate cortex. Some, in particular those ending in layer $4 \mathrm{AB}$, distributed more than 2 $\mathrm{mm}$ laterally, forming several clumps of terminal boutons. But even the most discrete terminations of single axons, those in layer $4 \mathrm{C}$, were found to radiate more than $600 \mu \mathrm{m}$. This amount of spread, which spans the dendritic fields of several postsynaptic cells placed end to end, certainly exceeds the dimensions necessary for a simple microanatomical explanation of the observed retinotopic order. Given this sort of arrangement, we are left with two possibilities: either the terminal distributions of afferent axons are very much smaller and better ordered in the macaque than they are in the cat, or the observed order derives from some factor other than the geometry of afferent inputs. Although the first explanation seems plausible, the second should not be ruled out. There are, after all, many neurons and interconnections in layer $4 \mathrm{C}$ and it would seem within their capacity to extract specific information from a scattered, partially overlapping collection of diffuse inputs. In other words, a precise retinotopic map could be generated to some extent within layer 4C (Barlow, 1981).

There are additional questions that need to be asked about the segregation of LGN afferents in the vertical domain. As noted above (Ferster and LeVay, 1978), single afferents in cat striate cortex seem capable of projecting to more than one cortical lamina. In the monkey we know that inputs to layers $1,4 \mathrm{~A}, 4 \mathrm{C} \beta$, and 6 derive from parvocellular LGN laminae (Hubel and Wiesel, 1972, 1977; Fitzpatrick et al., 1983), but do these inputs derive from separate populations of LGN neurons? Or do they occur as multiple collaterals of single large axon trunks? And how complete is the input segregation between $4 \mathrm{C} \alpha$ and $4 \mathrm{C} \beta$ ?

With these issues in mind, as well as the intent to lay a better foundation for further physiological studies of macaque striate cortex, we studied the terminations of individual afferent fibers in known thalamic input laminae. We used two techniques: microinjections of HRP into the white matter below striate cortex (Ferster and LeVay, 1978) and intracellular recording followed by iontophoretic injection with HRP (Gilbert and Wiesel, 1979; Bowling and Michael, 1980; Sur and Sherman, 1982). Both techniques yielded satisfactory results. However, the latter provided direct identification of thalamic afferents and in addition enabled us to distinquish parvoand magnocellular afferents from one another on the basis of receptive field organization (Wiesel and Hubel, 1966; Sherman et al., 1976; Dreher et al., 1977; Schiller and Malpeli, 1978; Lee et al., 1979). These studies have been reported briefly (Blasdel et al., 1981; Blasdel and Lund, 1982a, b).

\section{Materials and Methods}

HRP injections into while malter. Macaque monkeys (four Macaca fascicularis; one $M$. nemestrina) were anesthetized with an intramuscular injection of ketamine $(30 \mathrm{mg} / \mathrm{kg})$ and xylazine $(3 \mathrm{mg} / \mathrm{kg})$; then they were intubated. After transfer to a stereotaxic head holder, anesthesia was supplemented with nitrous oxide and oxygen $(2: 1)$. As the initial dose of ketamine wore off, anesthesia was gradually switched to halothane $(0.5$ to $1.5 \%$ ) in nitrous oxide and oxygen. Several small $2 \mathrm{~mm}$ $\times 2 \mathrm{~mm}$ craniotomies were drilled bilaterally over striate cortex, and the exposed dura was covered with $4 \%$ agar in artificial cerebrospinal fluid (CSF) (Feldberg and Fleischauer, 1960).

Pressure injections of HRP were made from glass micropipettes (15- $\mu \mathrm{m}$ pore diameter) glued with epoxy over the needle of a Hamilton syringe. After the pipette had been lowered to the correct depth by a stepping motor microdrive (Central Engineering Services, California Institute of Technology), the enzyme (a 10\% solution of Boehringer HRP in artificial CSF containing 3\% lyso- 
lecithin) was ejected by a second stepping motor microdrive. Between 1 and $5 \mathrm{nl}$ were injected in 0.06-nl steps over a period of 20 to $30 \mathrm{~min}$.

For iontophoretic injections, Microdot pipettes were drawn to a taper of 10 to $15 \mathrm{~mm}$ and backfilled with a $10 \%$ solution of HRP in artificial CSF ( $\mathrm{pH} 7.0$ ). In order to guarantee a large unclogged tip, we trimmed the pipette with a fine pair of scissors immediately before lowering it into the brain. Microscopic examination of successfully used pipettes revealed tip inner diameters of 40 to $70 \mu \mathrm{m}$. Electrophoretic deposition was accomplished by passing 1 to $5 \mu \mathrm{A}$ for 5 to $20 \mathrm{~min}$. In some instances the pipette was advanced slowly in $1-\mu \mathrm{m}$ steps over a total distance of $200 \mu \mathrm{m}$ while the enzyme was ejected.

Penetrations were always made at highly oblique angles (greater than $50^{\circ}$ with respect to vertical) in order to optimize our chances of obtaining filled axons that did not arborize in damaged regions of cortex. The yield of axons was greatly improved by recording the depth of the transition between layer 6 and the white matter during a preliminary penetration with a large-tipped platinum-iridium electrode (Wolbarsht et al., 1960). We suspect from both bulk filling and from intra-axonal filling experiments that the geniculo-cortical axons rise to superficial levels in the white matter and travel considerable distances just deep to layer 6 before entering the cortical neuropil.

For survival times, we relied initially on the previous work of Ferster and LeVay (1978), who found the most useful interval to lie between 6 and $18 \mathrm{hr}$. We have found, however, that survival times as short as $1 \mathrm{hr}$ and as long as $72 \mathrm{hr}$ also produce satisfactory results. At the end of the survival period, anesthesia was supplemented with Nembutal and the animal was perfused transcardially with a warm solution of $0.5 \%$ sodium nitrite in phosphatebuffered saline, followed by $2 \%$ paraformaldehyde and $1.25 \%$ glutaraldehyde in phosphate buffer, and a final graduated scries of phosphate-buffered sucrose solutions. The cranium was opened, and blocks of striate cortex containing the injection sites were removed and allowed to sit overnight in a stirred solution of phosphatebuffered $30 \%$ sucrose at $4^{\circ} \mathrm{C}$. Blocks were cut on a freezing microtome at $90 \mu \mathrm{m}$ in either the coronal or the sagittal plane on the following day. Cut sections were reacted with the improved diaminobenzidine (DAB)-cobalt method of Adams (1981), mounted, dried, and coverslipped. Filled axons were drawn using either $a \times 50$ or a $\times 100$ oil objective. Axons were chosen for analysis when their major trunks could be traced back into the injection site in the white matter or at the border of white matter and lamina 6 and when the terminal field appeared reasonably well filled.

Intra-axonal recording-Preparation. For physiological recording the animal received similar surgical preparation to that described above and was then paralyzed with pancuronium bromide $(0.1 \mathrm{mg} / \mathrm{kg} / \mathrm{hr})$ in an infusion of $10 \%$ dextrose. The animal was respirated with a $2: 1$ mixture of nitrous oxide and oxygen with enough $\mathrm{CO}_{2}$ added to maintain the concentration of end-tidal $\mathrm{CO}_{2}$ within normal limits. After a craniotomy had been drilled and a dural flap reflected, halothane anesthesia was replaced with barbiturate (thiopental sodium, 0.5 to 2.0 $\mathrm{mg} / \mathrm{kg} / \mathrm{hr}$, in conjunction with nitrous oxide and oxygen). Injections of dexamethasone and antibiotics were administered every $6 \mathrm{hr}$.

The animals' accommodation and pupils were relaxed with homatropine and the corneae were anesthetized with Ophthetic. Each cornea was provided with a hard contact lens whose radius of curvature was chosen so that the eye was in focus ( \pm 0.5 diopters) at $2 \mathrm{~m}$. The dilated eyes were refracted with a slit retinoscope, and the projections of the two foveae and optic disks were plotted on a tangent screen with the aid of a reversible ophthalmoscope. These projections were used to calculate eccentricity and to measure how far the eyes had diverged and torted following paralysis. Finally, each eye was provided with a $3-\mathrm{mm}$ artificial pupil, centered over the optic axis.

Recording. We drew pipettes with tapers of 15 to 20 $\mathrm{mm}$ from 1.2-mm Microdot tubing and backfilled them with a solution of $20 \% \mathrm{HRP}$ in $0.2 \mathrm{M}$ potassium acetate (pH 6.8). The pipette tip was then broken by touching it to the edge of a glass slide. Although the broken tip was never visible when viewed with a $\times 40$ objective, the electrode impedance, measured before and after breakage, was found typically to decrease from approximately 300 megohms to approximately 150 megohms (AC impedance measured at $200 \mathrm{~Hz}$ ).

Once the guard tube and craniotomy had been sealed with agar ( $4 \%$ in artificial CSF) and wax, the micropipette was slowly advanced in a series of $2-$ or $5-\mu \mathrm{m}$ steps. As the pipette approached a visually responsive unit, the process's activity usually could be distinguished for some time before it was actually impaled. This afforded an opportunity for studying its receptive field both extracellularly and (after penetration) intracellularly. During the period of extracellular study, we plotted the unit's receptive field properties to determine whether these resembled those of cells in the LGN (see below). If they did not we continued our search. For units satisfying our criteria of LGN afferents, however, we next attempted to penetrate the process by advancing the pipette slowly in a series of $1-$ or $2-\mu \mathrm{m}$ steps. Successful penetration of a process was indicated by a sudden drop in the DC potential (by at least 30 to $50 \mathrm{mV}$ ) and by the replacement of the unit's crisp extracellularly monitored activity with much larger (greater usually than $20 \mathrm{mV}$ ) action potentials which had a slower time course owing presumably to the nonlinear cable properties of our very high impedance electrodes.

Once we had entered a process and verified that its receptive field properties were not different from those determined extracellularly, we next passed $5 \mathrm{nA}$ anodal current for $5 \mathrm{sec}$ and replotted the receptive ficld. If this caused the unit to be lost, we resumed our search. If the unit was stable, however, we passed $5 \mathrm{nA}$ for $15 \mathrm{sec}$. Following this, we increased the current to 10,15 , and then to $20 \mathrm{nA}$. Always, though, the current was turned off after $15 \mathrm{sec}$ and the receptive field replotted in order to verify that the initially identified process remained impaled. In this fashion, we continued passing current until one of our checks revealed that the pipette had come out of the process or that the membrane was too badly damaged for us to continue monitoring activity. At 
that point, the pipette was withdrawn, a new one selected, and the entire procedure repeated at a new location, at least $2 \mathrm{~mm}$ distant. Final verification of an intracellularly recorded process was achieved by actually recovering the HRP-filled process, including the part that had been injected (e.g., see Figure $2 B$ ). For processes where we were able to do this (those processes included in our sample) we are confident that all correspond to ones that had been studied physiologically because (1) we never filled more than one process from a single injection site, and (2) in those cases where we deliberately iontophoresed HRP into the white matter (in an effort to fill many axons-see above), the amount of current required to produce even a noticeable injection zone was considerably greater (by several orders of magnitude) than the amounts used for intracellular injection.

Following the final injection, the animal was allowed to survive for at least 2 additional hr. In preliminary tests, using cats, it was found that survival times greater than $20 \mathrm{hr}$ resulted in HRP leakage from the filled arborizations. In the macaque monkey, however, such leakage seems not to be a problem, and we have recovered excellently preserved processes that we filled as long as $72 \mathrm{hr}$ before the animal was perfused. Perfusion procedures and subsequent histological preparation have already been described.

Receptive field analysis. Physiological recording coupled with the careful mapping of visual receptive fields provided our principal means of identifying thalamic axons. We judged a process to derive from the LGN if it (1) had a high spontaneous activity in conjunction with a tightly coupled response to visual stimulus presentation, (2) lacked orientation selectivity, (3) was monocular, (4) exhibited an antagonistic relationship between center and surround (although this is not an essential criteriontype II cells, for example, have no surround-all but one of our axons in fact satisfied it), and (5) had a receptive field center that, for a given eccentricity, was commensurate in size with that of an LGN cell. Because there are no other known sources of afferent input to macaque striate cortex that can satisfy these criteria, we believe that processes identified in this fashion, in fact, derive from the LGN. It is perhaps worth pointing out that other tests, such as electrical stimulation, are of little additional value in proving thalamic origin. Highly coupled responses to electrical stimulation at the optic chiasm, for example, might indicate that a process receives fairly direct visual input; but so do tightly coupled visual responses (criterion 1). Stimulation within the LGN is technically difficult and unreliable due to the unfavorable nature of current spread in grey matter and the large volume of tissue that must be stimulated if one is to cover a reasonable range of eccentricities for both the parvo- and the magnocellular laminae. And responses to electrical stimulation in the optic radiation can hardly be expected to guarantee a thalamic origin when this pathway also serves as a major conduit for striate afferents from such nongeniculate sources as the claustrum, pulvinar, MT, and even the corticofugal projections of layer 6 striate cells which have recurrent collaterals in striate cortex. All of these alternate possibilities would be difficult or impossible to rule out in the absence of careful receptive field analyses.
Once a recorded process was thought to derive from the LGN, we used a color video monitor (Mitsubishi C3910 , raster linearity and luminance stability better than $2 \%$ and $1 \%$, respectively) to scrutinize further its receptive field organization. The monitor was driven by an LSI-11/ 23 computer and a video image processor containing two bit planes of $512 \times 512$ pixels expressed through a 24-bit color lookup table that provided 256 grey levels for each color phosphor (i.e., $2^{24}$ or 16 million color combinations). Each of the 256 broad band grey levels had been carefully calibrated with a photopically corrected photodiode (United Detector Technology, PIN-10AP). Using a light, dark, or optimally colored spot (or slit) we first plotted the perimeter of the receptive field center. We then tested the region inside this perimeter for flash responsiveness (ON versus OFF). During the course of these tests, we adjusted the size and contrast of the test spot (against a background luminance of $5 \mathrm{~cd} / \mathrm{m}^{2}$ ) in order to determine the peak values of the area/contrast sensitivity curve. These values enabled us to delineate more accurately the limits of the receptive field center and also provided a useful indication of the contrast sensitivity of the cell (contrast defined as $\Delta I /(2 \mathrm{Im})$ where $\Delta I$ refers to the change in luminance and Im to the average mean luminance at the edge of the test spot). This measure of contrast sensitivity reveals a clear-cut difference in the contrast sensitivities of different populations of LGN cells and afferent axons in striate cortex and, in this respect, resembles measurements of Shapley et al., (1981) and of Lennie and Derrington (1981). ${ }^{3}$ Once the receptive field center had been satisfactorily determined, the center and surround were tested separately for color selectivity and the center was, in addition, tested for the presence of a sustained or transient response. A response of less than 300- msec duration was judged to be transient, whereas responses lasting longer than 1 sec were defined as sustained. Of the axons chosen for filling, none had responses of intermediate duration.

Our criteria for classifying and distinguishing parvocellular responses from those of the magnocellular laminae are those of Wiesel and Hubel (1966) as modified by

\footnotetext{
${ }^{3}$ The measurements, in fact, differ due to the different techniques that have been used for measuring contrast threshold. Our determination relies on responses to the presentation of a stimulus with sharp edges where the contrast is modulated between zero and a test value, $A$, at a frequency of $0.5 \mathrm{~Hz}$. The measurements of Shapley et al. (1981) and others, on the other hand, derive from responses to sinusoidal gratings that are made to drift across the visual field at a rate of 4 cycles/sec. Since the contrast between center and surround that is produced by a drifting sinusoidal grating changes from $+A$ to $-A$ (instead of from $+A$ or $-A$ to zero), this measure should yield sensitivity values that are at least twice as high as those derived by us. The different modulation rates $(4 \mathrm{~Hz}$ versus $0.5 \mathrm{~Hz}$ ) are also expected to produce different threshold values. As a consequence of these differences, and perhaps also due to different interpretations of threshold responses, the LGN neurons that we tested during preliminary recordings in one of our macaque monkeys displayed contrast thresholds that were higher, by a factor of three, than those reported by Shapley et al (1981). In spite of these scaling differences, the cells that we recorded in the parvo- and magnocellular LGN laminae were found to have nonoverlapping distributions of contrast sensitivity. Although type III magnocellular cells were observed to have contrast thresholds between 0.1 and 0.2, parvocellular neurons (types I, II, and III) were never observed to have contrast thresholds below 0.3 .
} 
several more recent observations (Sherman et al., 1976; Dreher et al., 1977; Lennie and Derrington, 1981; Shapley et al., 1981; Marrocco et al., 1982). On the basis of these investigators' work, it is reasonable to conclude that units giving transient responses to broad band stimuli and displaying low contrast thresholds may be considered to derive from magnocellular LGN laminae, whereas units with sustained, broad band receptive fields and high contrast thresholds, or units with color-opponent receptive fields, almost certainly derive from parvocellular LGN laminae. One additional piece of evidence that we used in making a magno/parvo distinction rests on the observation (Sherman et al., 1976; G. G. Blasdel, D. Fitzpatrick, and J. S. Lund, manuscript in preparation) that magnocellular LGN cells have substantially larger receptive field centers than parvocellular ones.

Computer reconstruction. Some filled processes were reconstructed in three dimensions so that they could be rotated and inspected from different angles. We did this with the aid of a Leitz Dialux microscope linked to an LSI-11 computer, color video monitor, and graphics digitizer. The stage on the microscope was connected to three orthogonally arranged linear position transducers which delivered highly accurate coordinate information (within $0.25 \mu \mathrm{m}$ for the Z-axis) to the computer. A graphics tablet (Summa Corp.) was used to control a cursor on a color television screen that could be seen through the drawing tube of the microscope. Due to this particular arrangement, the video image appeared superimposed on the histological specimen and followed movements of the stage. By knowing which slide was being drawn and by reading coordinates from the stage position transducers, the computer was able to tabulate points of interest (such as boutons, axon branches and trunks, laminar boundaries, etc.) as a list of four-dimensional vectors-the fourth dimension serving to identify the object of interest. In this manner, and through the additional subsequent use of rotational, translational matrices, the axon could
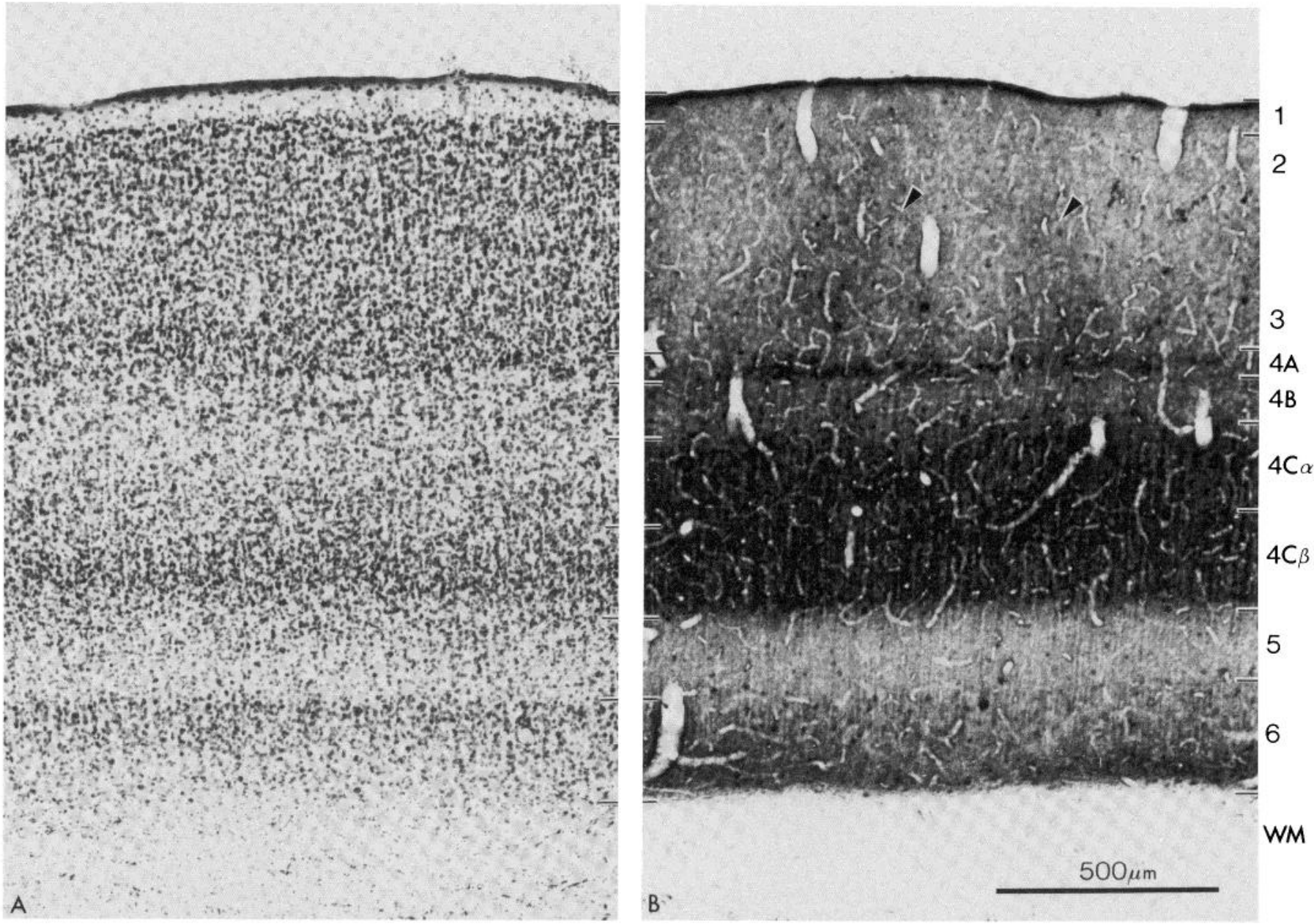

Figure 1. Recent evidence (Hubel and Livingston, 1981; Fitzpatrick et al., 1983) suggests that cytochrome oxidase may be used to indicate zones of thalamic input. This figure depicts photomicrographs from two sequential, $40-\mu \mathrm{m}$, parasagittal sections of macaque striate cortex. The region shown is taken from the occipital operculum just behind the lunate sulcus. The tissue in $A$ has been stained with thionin for Nissl substance, and the tissue in $B$ has been stained for cytochrome oxidase. As can be seen from these photomicrographs, laminae $4 \mathrm{C}$ and $4 \mathrm{~A}$ are prominently stained in the cytochrome oxidase material. This stain has the added advantage of revealing cytochrome-rich "puffs" in layer 3 (arrows in $B$ ) which are presumed sites of terminating axons from the intercalated laminae of the LGN (Fitzpatrick et al., 1983). Accordingly, we have chosen cytochrome oxidase staining as our standard for defining layers $4 \mathrm{~A}, 4 \mathrm{C}$, and 6 . This definition is particularly useful since a similar pattern of staining, probably from cytochrome oxidase as well, is seen in tissue that has been reacted for DAB-cobalt according to Adams' (1981) protocol (e.g., see Fig. 5). 
be displayed at any desired magnification, position and orientation. Because the Adams cobalt-intensified DAB reaction does not entail the use of alcohol before the tissue is mounted on slides, there is little or no shrinkage of the section. During subsequent dehydration and coverslipping, however, there is considerable shrinkage in section thickness; and the computer, therefore, was programmed to normalize each section to a thickness of 90 $\mu \mathrm{m}$.

\section{Results}

Cortical layers. The lamina numbering for macaque striate cortex used in this study is that used earlier by Lund (1973) with the following changes. Recent evidence (which relies on the likelihood that cytochrome oxidase accurately indicates the presence of thalamic terminals, Hubel and Livingston, 1981; Fitzpatrick et al., 1983) suggests that the zone of thalamic input in $4 \mathrm{C}$ reaches slightly higher than had previously been suspected. As one can see from comparing Figure $1, A$ and $B$, the band of heavy cytochrome label in layer $4 \mathrm{C}$ is somewhat wider than the $4 \mathrm{C}$ band as previously defined by Lund (1973; see Fig. 1). Inasmuch as the results of this paper are more consistent with a thalamic input zone that is defined by cytochrome oxidase staining than they are with the previously suggested boundaries, we have moved the boundary between layers $4 \mathrm{C} \alpha$ and $4 \mathrm{~B}$ upward slightly. Thus $4 \mathrm{C}$ is defined by rich cytochrome oxidase staining and continues to represent a major zone of thalamic input. Lamina 4B, however, becomes somewhat narrower than previously defined (Lund, 1973). For similar reasons we have expanded layer $4 \mathrm{~A}$ upward to include the zone above the single dark-staining line of cells that traditionally has been used to define this lamina. This zone, which is indicated by a narrow dark band in the cytochrome section (Fig. $1 B$ ), has been shown through orthograde degeneration to correspond to the actual zone of thalamic axon termination (Hubel and Wiesel, 1972).

General comments. One example of a large iontophoretic injection into the border zone between layer 6 and
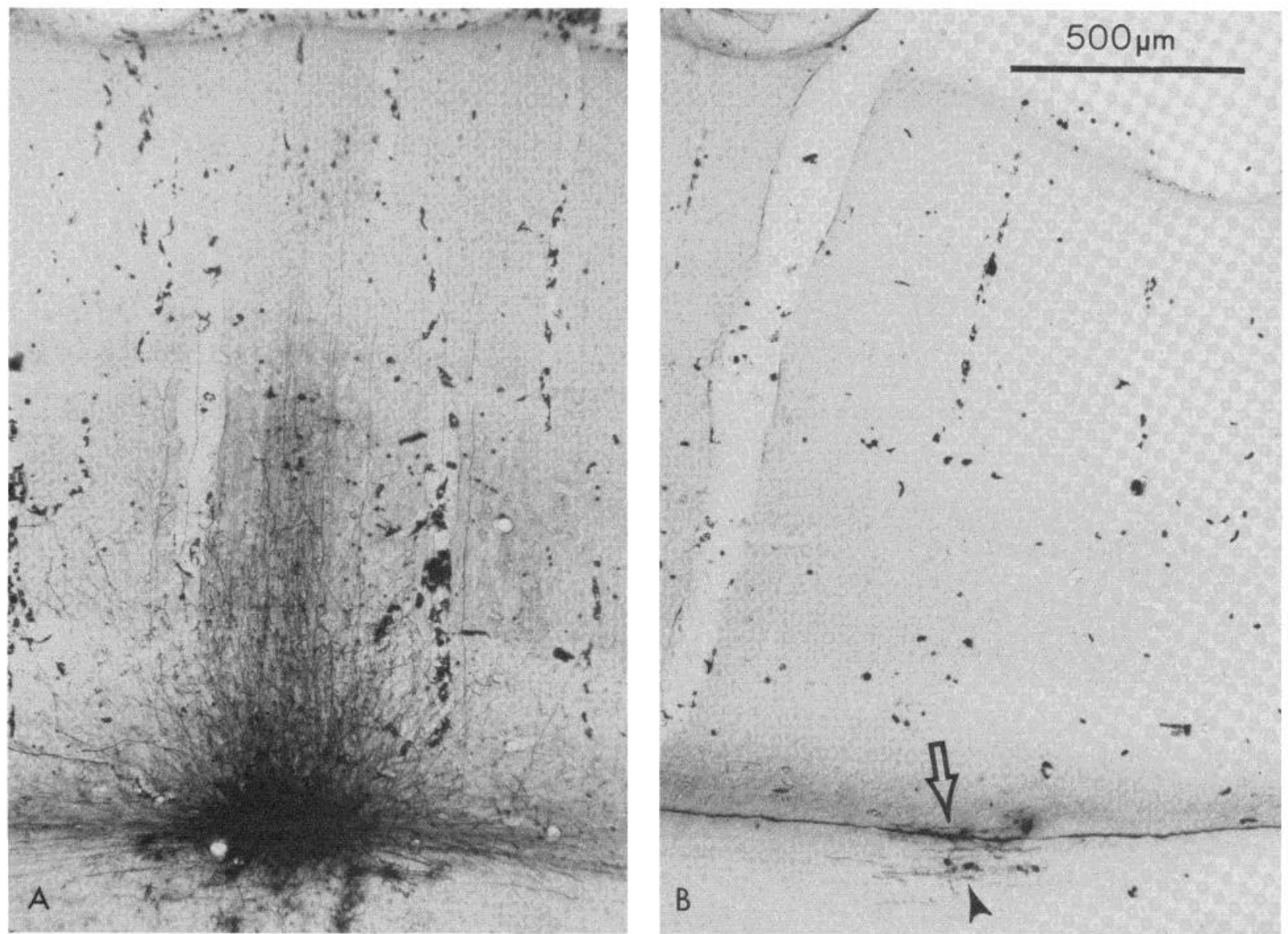

Figure 2. A, Site of an iontophoretic injection of HRP into the white matter of striate cortex. This injection was made by first locating the depth of the white matter/layer 6 boundary with a metal microelectrode, lowering an HRP-filled pipette (40 to 70 $\mu \mathrm{m}$ tip diameter) to the appropriate depth, and then passing a small amount $(0.5 \mu \mathrm{A})$ of anodal current for 5 min. Note the labeled axon trunks running through cortical grey matter. Most afferents studied were recovered some distance from the injection site, and their preterminal trunks could usually be traced back to the white matter, thus reducing the possibility that they could have derived from intrinsic local neurons. $B$, Site where a single axon, with terminal arborization in $4 \mathrm{C} \alpha$, has been penetrated, recorded, and intracellularly injected with HRP. The axon was physiologically determined to have a transient, OFF-center, broad band receptive field, similar to the type $3 \mathrm{Y}$ of Dreher et al. (1976). Due to the trauma of current passage, the axon membrane appears rough and damaged in the region of the injection (open arrow). The small solid arrow points to a fibrous astrocyte that has taken up some of the HRP that leaked from the damaged axon membrane. 
the white matter is shown in Figure $2 A$, and an example of an iontophoretically filled axon appears in Figure $2 B$. Both techniques led to the recovery of 38 axons with discrete terminations in known LGN recipient layers of striate cortex. Each axon had a single primary projection; for most of those ending in $4 \mathrm{C} \alpha$ and for that ending in
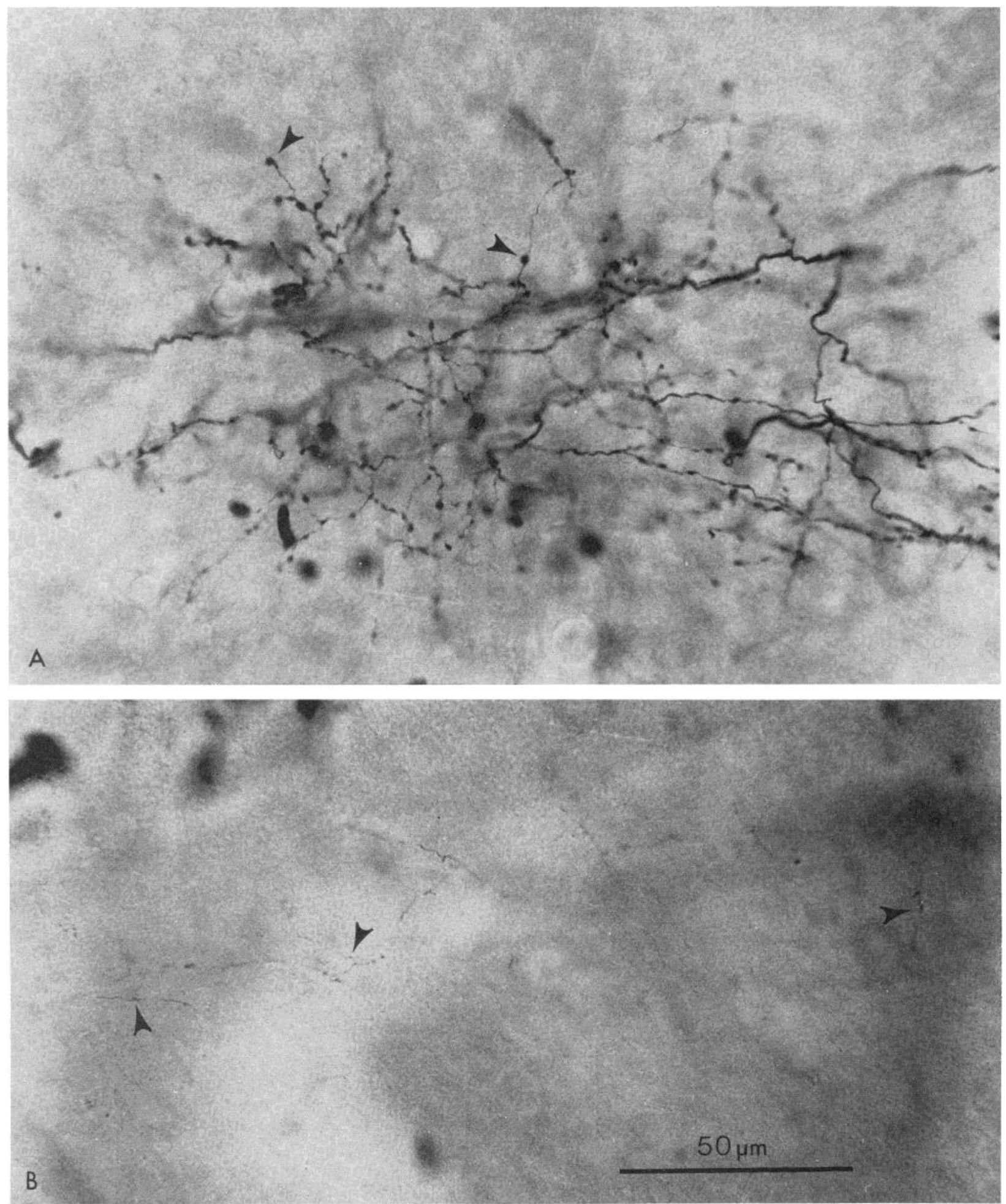

Figure 3. A, Photomicrograph of HRP-filled terminals belonging to an intracellularly injected axon arborizing in lamina $4 \mathrm{C} \alpha$. Arrows point to filled boutons. Typically, the terminal boutons were found to vary between 1 and $2 \mu \mathrm{m}$ in diameter. Previous work (Winfield et al., 1981) has shown that each bouton gives rise to one or more "en passant" synapses. Scale as in $B$. $B$, Photomicrograph of the delicate HRP-filled terminal branches that were found in layer 1 following intracellular recording and injection of an LGN type II (blue-ON) axon in the white matter. As can be seen from this photograph, the boutons (arrowed) are extremely small $(0.5$ to $1 \mu \mathrm{m})$ and the connecting processes are long and so thin that they approach the resolving power of the light microscope. This axon is drawn in its entirety in Figure 17. 


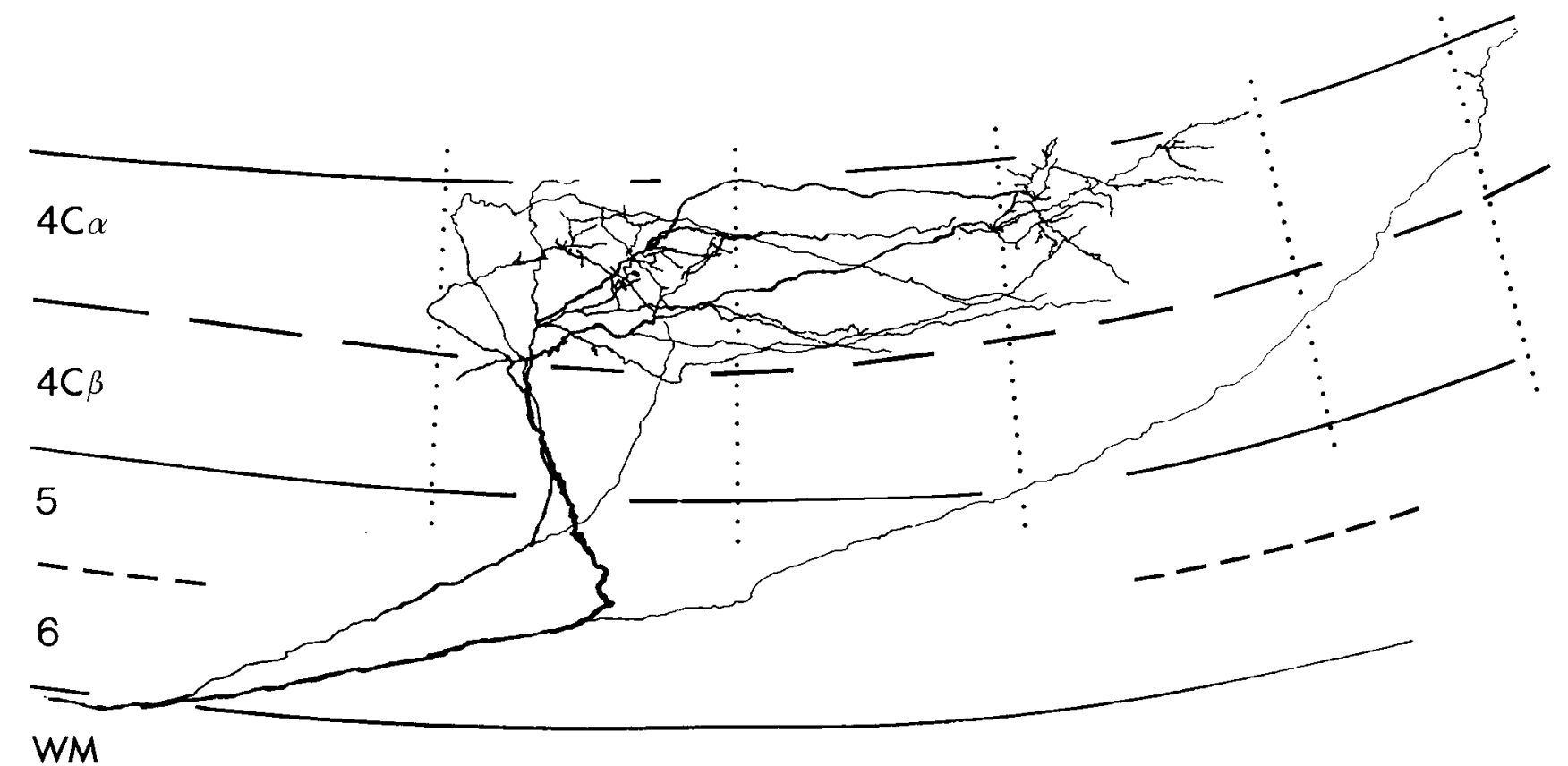

WM

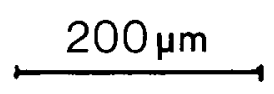

Figure 4. Drawing of an afferent axon, with terminal arbor in layer $4 \mathrm{C} \alpha$, that was filled following a white matter injection of HRP. Note that the terminal boutons are confined to layer $4 \mathrm{C} \alpha$, where they appear as three discrete clumps, and that no collateral branches are given off to other laminae. Dotted vertical lines correspond to the boundaries of ocular dominance columns which were inferred from autoradiographic labeling of the ocular dominance domains in the same sections (see Fig. 18). The three clumps of boutons fit within only the right eye (labeled) set of bands.

layer 1 , this primary projection was accompanied by a finer secondary arborization in layer 6 . Those with primary arbors in $4 \mathrm{~A}$ sometimes had fine collaterals in lamina 2-3. Axons arborizing in more than two laminae, however, were never observed. Eleven axons (six from intracellular injections) were observed to arborize in layer $4 \mathrm{C} \alpha, 21$ (two intracellular) in $4 \mathrm{C} \beta$, four in layer $4 \mathrm{~A}$, and one intracellularly recorded axon arborized in layers 1 and 6. Afferents to layer 6 occurred only as collaterals to axons having more major arborizations in other laminae.

Because of the nature of bulk filling, it is important to consider whether axons traced from an injection site are part of a larger arbor which had started to divide from the parent trunk at a point proximal to the injection site. In the case of axons projecting to $4 \mathrm{C} \alpha$, our reasonably large sample of intracellularly filled axons (filled both proximal and distal to the injection points) gives us confidence that this is not a problem for this particular group. In the case of axons arborizing in $4 \mathrm{C} \beta$, where our intracellular filling was less successful, we are still reasonably confident that each axon projects to a single, tightly confined terminal field because (1) we have many examples of such circumscribed "terminal fields"-all of very similar dimensions; (2) they occur in isolation from one another; there are no adjacent processes that might have been accidentally missed; and (3) our two intracellularly filled examples are consistent with single, discrete zones of terminal arborization.

The morphology of fine terminal processes in layers $4 \mathrm{C} \alpha, 4 \mathrm{C} \beta$, and $4 \mathrm{~A}$ was similar in appearance. Figure $3 A$ shows a high power photomicrograph of part of a terminal arborization in layer $4 \mathrm{C} \alpha$. The axon has a characteristic serial beaded appearance similar to that described by Ferster and LeVey (1978) for afferent axons in cat striate cortex. Typically, the beads vary between 1 and $2 \mu \mathrm{m}$ in diameter (measurements not corrected for shrinkage), and occasional dilatations may be found with diameters as great as $3 \mu \mathrm{m}$. Previous electron microscopic work (Winfield et al., 1981) has shown that each bead or dilatation can give rise to one or more "en passant" synaptic contacts for the $\alpha$ subdivision but probably no more than one for the $\beta$ division. The axon processes in layers 1 and 6 stood in marked contrast in their fineness and reduced number of boutons. The serial beads in layer 1, for example (see Fig. $3 B$ ), varied between 0.5 and $1 \mu \mathrm{m}$ in diameter and were connected by long and extremely fine axon segments whose thickness came close to the resolving power of the light microscope.

Figure 5. Three examples of HRP-filled terminal arbors in layer $4 \mathrm{C} \alpha$ that were observed following intracellular injections of two axons with HRP. The terminal fields shown in $A$ and $B$ are different portions of the same axon arbor, but the terminal field depicted in $C$ was obtained from a different animal. Unlike the axon shown in $A$ and $B$, the one appearing in $C$ gave off a few very fine collaterals in lower lamina 6 (arrow). Both axons gave transient ON responses when tested with a flashing spot of white light, and neither demonstrated color selectivity. The axon seen in $C$ is drawn in its entirety in Figure $6 . A, B$, and $C$ are all photographed at the same scale. 

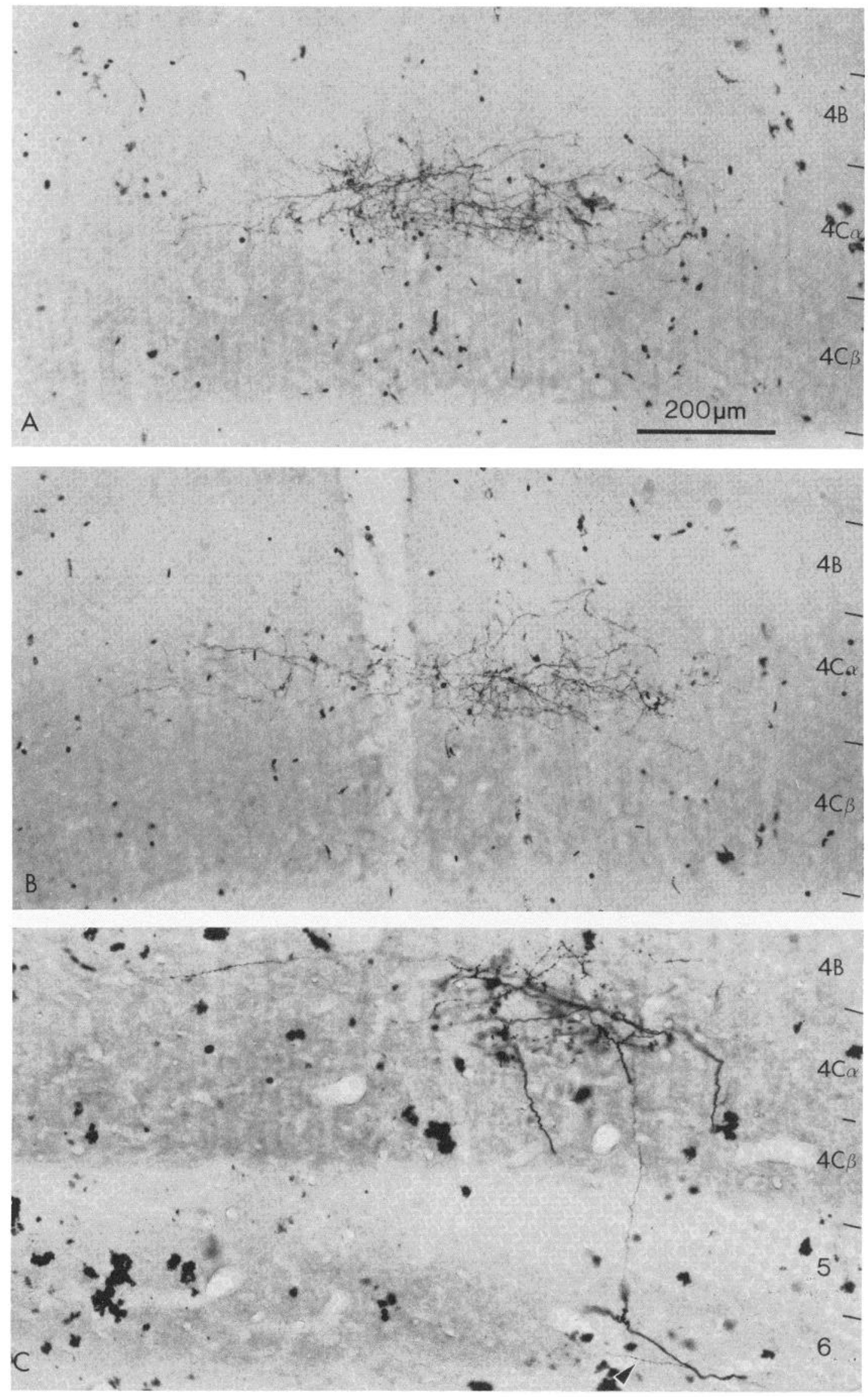

Figure 5 
One feature which all afferent axons shared in common was a general asymmetry in their projection patterns through the neuropil. Unlike previously proposed candidates for thalamic afferents (Valverde, 1971; Lund, 1973), none rose vertically above the point of entry from the white matter and none spread symmetrically above this point upon reaching a particular cortical lamina. All axons rose through the cortical neuropil at a marked slant and arborized to one side in a highly asymmetrical way (see Fig. 11). The horizontal displacement frequently reached $800 \mu \mathrm{m}$.

Axons terminating in layer 4C $\alpha$. Microinjections of HRP into the white matter have yielded so far five axons with terminal arborizations in layer $4 \mathrm{C} \alpha$. Presumed to derive from cells in the magnocellular laminae of the
LGN (Hubel and Wiesel, 1972), each of these axons arborizes over a large area within $4 \mathrm{C} \alpha$. One example, shown in Figure 4, reveals a process with three arborizations. Except for a few terminals that can be traced for short distances into layers $4 \mathrm{~B}$ and $4 \mathrm{C} \beta$, no collaterals were found in other laminae (but see below).

We have subsequently recorded intracellularly from axons in the white matter before filling them individually with HRP. This has led to the successful recovery of six axons with primary terminations in layer $4 \mathrm{C} \alpha$ (see Fig. $5)$. Photographs of three representative sections containing labeled terminal portions of $4 \mathrm{C} \alpha$ axons appear in Figure 5. Three of the axons had monocular ON-center receptive fields, two had monocular OFF-centers, and one gave a strong and highly phasic OFF-discharge to

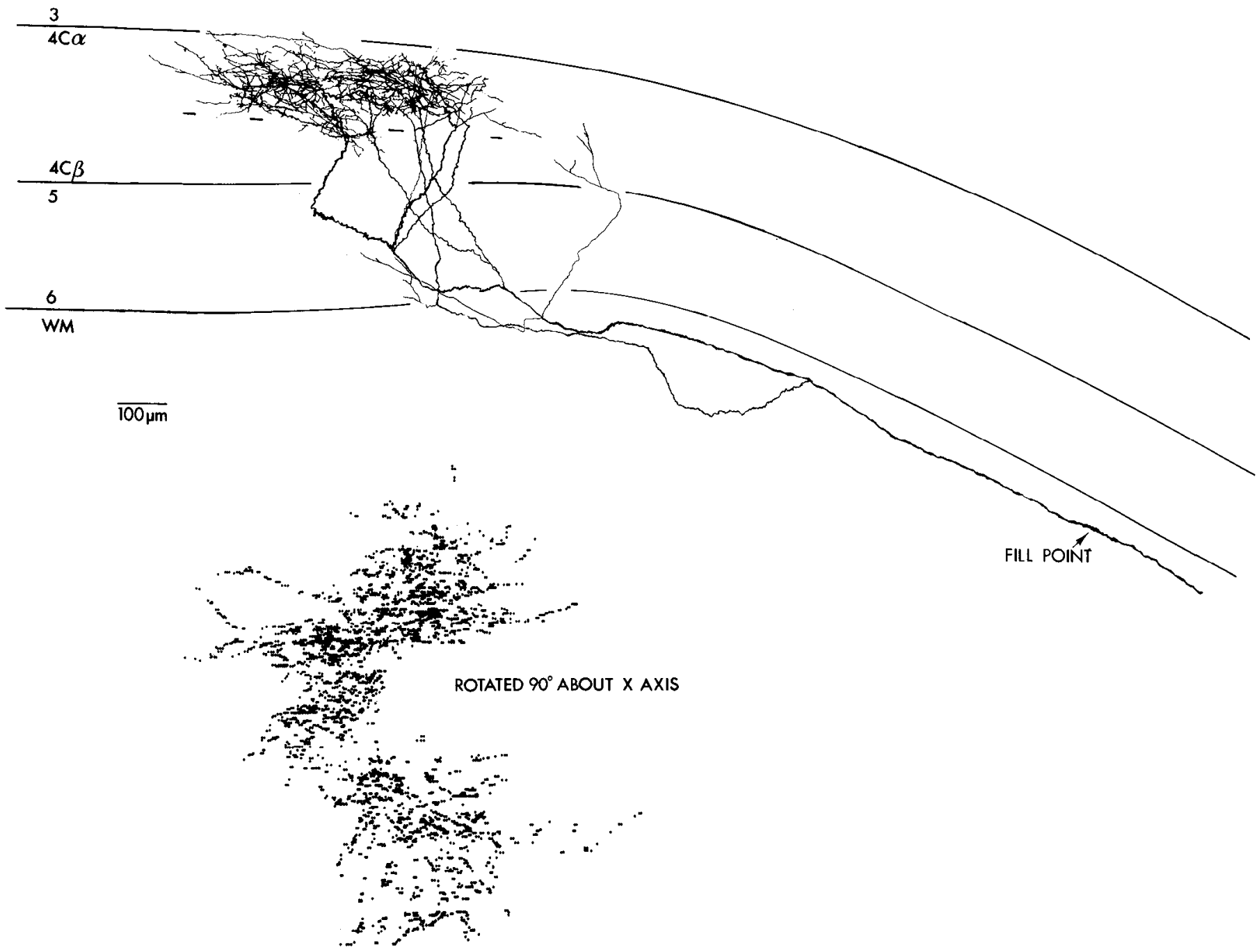

Figure 6. Intracellularly recorded and filled axon with terminal arborization in layer $4 \mathrm{C} \alpha$. This axon has been reconstructed from 11 serial, $90-\mu \mathrm{m}$ sections of striate cortex through which it arborized. A photomicrograph of one of these sections appears in Figure 5C. Physiologically, this axon had a monocular ON-center receptive field, $1^{\circ}$ in diameter and located $13^{\circ}$ in the contralateral visual field, and gave a highly transient ON-response when tested with a flashing spot of light. The axon had a low contrast threshold (0.1) and showed no apparent selectivity for color. In order to gain a better appreciation for the terminal spread of this axon, we used a computer microscope to reconstruct the positions of terminal boutons in three dimensions so that the imagecould be rotated $90^{\circ}$ about the $\mathrm{X}$-axis and viewed en face. The resulting distribution appears at the bottom of the figure as a $\mathrm{C}$-shaped band within $4 \mathrm{C} \alpha$. The terminals in this band cover a surface area of $0.4 \mathrm{~mm}^{2}$; if the band is straightened out, it appears $1.2 \mathrm{~mm}$ in length and $0.3 \mathrm{~mm}$ in width. It is presumed that this band corresponds to the ocular dominance territory of one eye. If so, it is interesting that fine projections can be traced into adjacent regions which, presumably, receive inputs predominantly from the other eye. 
light shown in one eye; but because we were unable to localize its receptive field, we have no direct evidence that this axon in fact derived from the LGN (although from its terminal morphology and from its temporally, tightly coupled visual responses, such a derivation would appear likely). All of the characterized axons responded phasically and displayed high sensitivity to luminance contrast (contrast threshold 0.10 to 0.15 ). Color selectivity was not apparent, and morphologically there were no marked differences between the ON-center and the OFFcenter axons. The axonal fields of the two OFF-center axons were somewhat smaller than those of the three

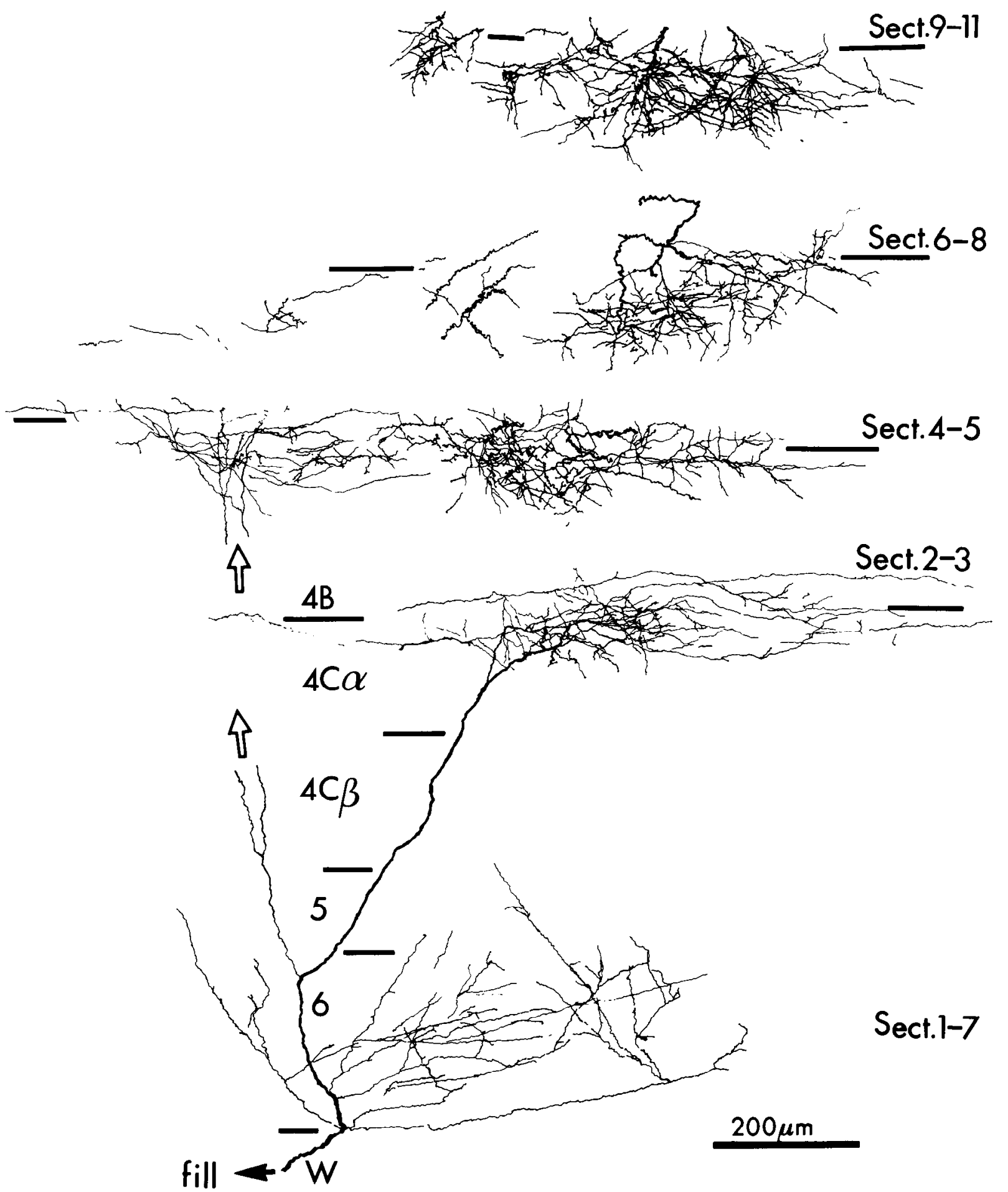

Figure 7. Drawing of an afferent axon that has been intracellularly injected with HRP. Terminal arbors occur in lower lamina 6 (tilt in the section series makes it appear to fill lamina 6-in fact, the arbor is confined largely to the lower half) and in the upper half of layer $4 \mathrm{C} \alpha$. The prolific arbor in $4 \mathrm{C} \alpha$ is drawn as several sets-each comprising two to three sections to avoid overcomplexity. The areal distribution $\left(0.56 \mathrm{~mm}^{2}\right)$ of this axon's terminal field, seen from above, appears in Figure 8 . This axon was physiologically identified as monocular and transient, with an ON-center, type III receptive field that resembled units of the magnocellular geniculate laminae (Wiesel and Hubel, 1966; Dreher et al., 1976; Schiller and Malpeli, 1978; Lee et al., 1979). 
ON-center axons; however, this is believed to be the result of less complete filling. Axon trunks, measured at several points in the white matter, ranged between 2 and $5 \mu \mathrm{m}$ in diameter for individual fibers.

One axon that had an ON-center receptive field located at $13^{\circ}$ eccentricity is represented in Figure 6. Part of this axon also appears in Figure $5 C$. From the reconstruction in Figure 6 it appears that this axon extends laterally for about $800 \mu \mathrm{m}$. The appearance is deceptive, however, since the figure represents a collapsed sequence of 11 sections, each about $90 \mu \mathrm{m}$ wide. In order to get a better appreciation of the relation between this axon and the retinotopic map in layer $4 \mathrm{C}$, we, therefore, reconstructed the terminal arborization in three dimensions (with the aid of a computer microscope) so that it could be rotated $90^{\circ}$ about the $\mathrm{X}$-axis and viewed en face. The resulting image, which appears at the bottom of Figure 6 , reveals that the terminal arborization extends $1 \mathrm{~mm}$ by $0.8 \mathrm{~mm}$. Within this space, however, the terminals appear clustered in a stripe-like fashion that follows a curved Cshaped trajectory. If this curved band is straightened, it assumes a width of $0.3 \mathrm{~mm}$ and a length of $1.2 \mathrm{~mm}$. We counted 3085 boutons which covered a total surface area of $0.4 \mathrm{~mm}^{2}\left(7.7 \times 10^{3}\right.$ boutons $\left./ \mathrm{mm}^{2}\right)$. If the stripe-like arrangement of these boutons corresponds to a single ocular dominance domain, as seems likely, it is interesting that sparse projections can be seen spreading horizontally into neighboring domains that presumably correspond to the other eye.

One major difference between intracellularly filled $4 \mathrm{C} \alpha$ axons and those derived from white matter HRP injections concerns the filling of finc terminal processes, particularly the fine collaterals in layer 6 . As noted earlier, no such lamina 6 collaterals were seen following white matter injections. Although this was also the case for some intra-axonally recorded and filled processes (e.g., Fig. 5, $A$ and $B$ ), others definitely had sparse and exceedingly fine collaterals in lower layer 6 (which is thought to receive magnocellular thalamic input; Hendrickson et al., 1978). One example appears in Figures $5 C$ (see arrow) and 6 . It should be stressed, however, that these collaterals are extremely fine and unlikely to be seen except with the dense filling that is achieved by intracellular injection.

One axon that was physiologically identified as having a highly transient, ON-center receptive field, $8^{\circ}$ in the inferior visual field, appears in Figure 7. Even though this axon had response properties that were similar to those of the ones shown in Figures 5 and 6 , it has a rather different morphology and distribution. The terminals in lower layer 6 , for example, are more pronounced than any observed to accompany other $4 \mathrm{C} \alpha$ axons. In addition, the upper arborization fills only the top half of layer $4 \mathrm{C} \alpha$. The terminal distribution is reconstructed in four sets (Fig. 7) in order to illustrate the extensive lateral spread within $4 \mathrm{C} \alpha$. When viewed from the pial surface (Fig. 8), the terminal field in $4 \mathrm{C} \alpha$ is seen to occupy two parallel stripes, each about $300 \mu \mathrm{m}$ wide, separated by a vacant region which is also about $300 \mu \mathrm{m}$ wide that runs perpendicularly into the $17 / 18$ border. The two collateral arborizations in lamina 6 probably underlie the upper layer patches; but due to problems with reconstructing sections that are mostly oblique to the pial surface, they appear offset.
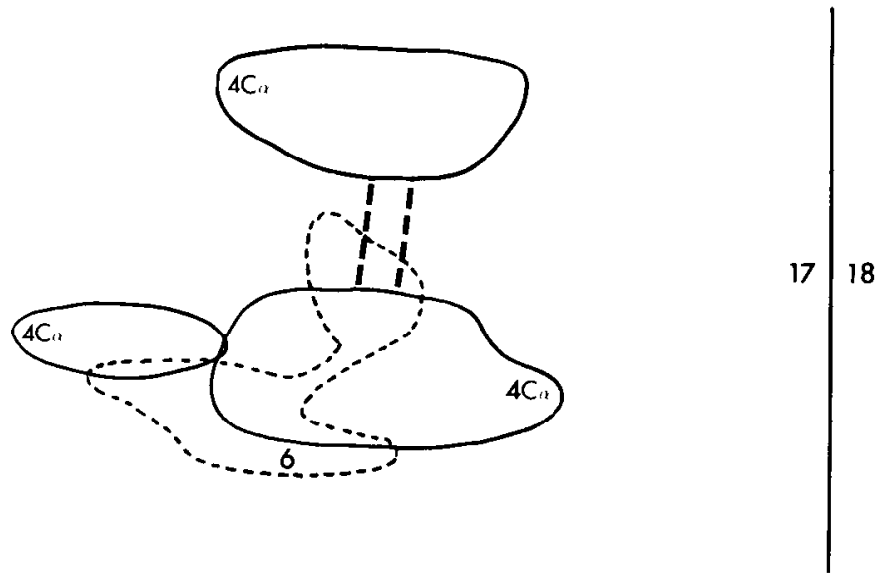

$500 \mu \mathrm{m}$

Figure 8. The areal distribution of terminal processes of the axon drawn in Figure 7, shown as viewed from the pial surface, within laminae 4C $\alpha$ and 6 . Areas enclosed by solid lines indicale the distribution in lamina $4 \mathrm{C} \alpha$; areas enclosed by fine broken lines indicate the terminal area in lamina 6 . The terminal field in $4 \mathrm{C} \alpha$ covers a total area of $0.56 \mathrm{~mm}^{2}$, which it occupies in two parallel, oval areas, each about $300 \mu \mathrm{m}$ wide, separated by a vacant region that is crossed by stout axon trunks (thick broken lines). The two collateral arborizations in lamina 6 probably underlie the upper layer patches, but in reconstructing these fields, from sections cut oblique to the pial surface, they appear offset. It is suggested that the two areas occupied by the terminals of this axon correspond to the ocular dominance domains of one eye because these are known to intersect the $17 / 18$ border (shown at its actual, relative location) at right angles (LeVay et al., 1975).

Axons terminating in layer $4 C \beta$. We have recovered 21 axons with terminal arborizations in layer $4 \mathrm{C} \beta$. Nineteen of these were derived from white matter injections of HRP. All have a highly stereotyped appearance in which the terminal field fills the depth of layer $4 \mathrm{C} \beta$ and spreads no further than $200 \mu \mathrm{m}$ laterally; usually for each axon a few collaterals spread into $4 \mathrm{C} \alpha$, but we have not seen collaterals terminating in other laminae. Photomicrographs and reconstructions of representative axons appear in Figures 9 to 14. Among the shared features of these axons are the tight terminal clusters of boutons (with a density of $7.4 \times 10^{3}$ boutons $/ \mathrm{mm}^{2}$ for a well filled one) and the fact, noted earlier, that trunks typically enter the grey matter at some distance from the point of final termination. One extreme example of this sort of asymmetry is shown in Figure 11 where an axon was found to travel through layer $4 \mathrm{C}$ (at the border between the $\alpha$ and the $\beta$ subdivisions) for some $800 \mu \mathrm{m}$ before finally giving rise to a terminal arbor. In this figure a Golgi-impregnated neuron, typical of those found in lamina $4 \mathrm{C} \beta$, is shown for comparison. The neurons of layer $4 \mathrm{C} \alpha$ are only slightly larger in dendritic spread (Lund, 1980) than those of $4 \mathrm{C} \beta$.

Although there are many compelling reasons for believing that these axons derive from LGN somata (see "Discussion"), we have recently obtained direct evidence from intracellular recordings. Owing to an extremely small average trunk diameter $(0.5$ to $1 \mu \mathrm{m}$ for this particular axon group), intracellular recording has been difficult; nevertheless, so far we have recovered two processes 

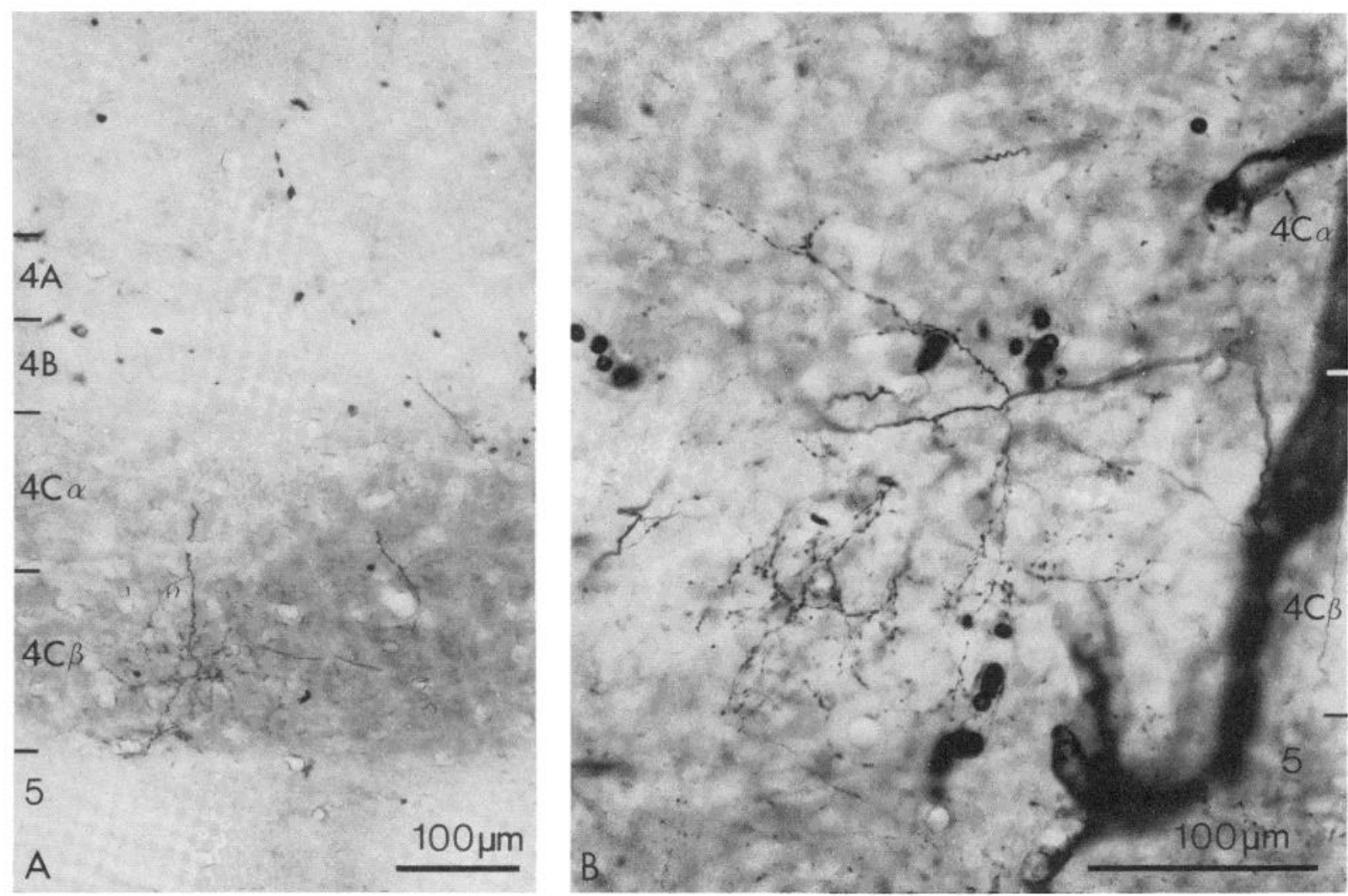

Figure 9. Photomicrographs of two axons with specific terminations in layer $4 \mathrm{C} \beta$. The arborization in $A$ was recovered from an intracellularly injected axon that was shown physiologically to have a blue-ON center and a (red + green)-OFF surround. The entire axon is reconstructed in Figures 13 and 14. The arborization appearing in $B$ was recovered following a white matter injection of HRP. It appears in its entirety in Figure 10 (right side).

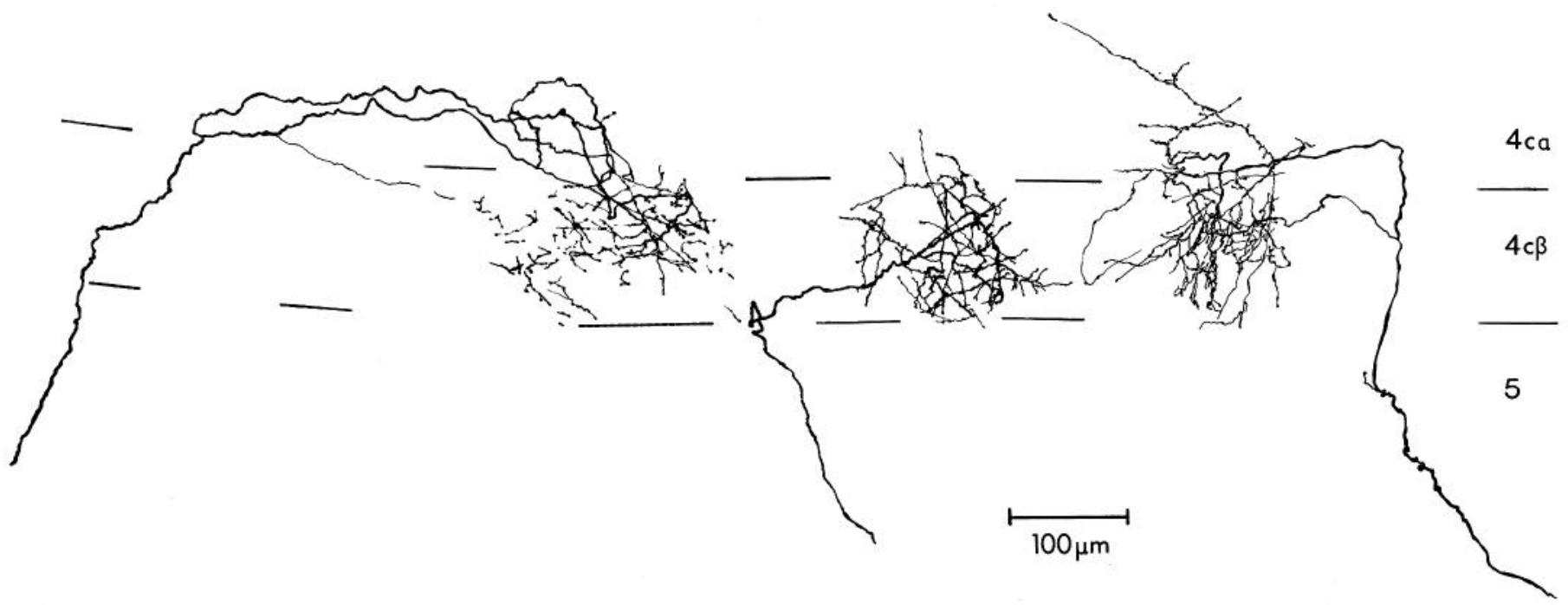

Figure 10. Drawings of three HRP-filled axons (filled from white matter injections of HRP) whose terminal arborizations are in lamina $4 \mathrm{C} \beta$. The left-hand example was less strongly filled than the other two examples, and the fine trunks were often hard to trace. However, there were no other labeled processes in the vicinity, and the HRP-filled boutons certainly seemed to belong to this axon. The full extent of the preterminal trunks back to the injection sites have not been included in this figure. These axons are typical of all the axons (21) found to arborize in this layer. As one can see from these reconstructions, they are highly stereotyped in appearance. When viewed en face, the axonal fields are roughly circular (see, for example, Fig. 14) and never extend more than $200 \mu \mathrm{m}$ laterally (most spread less than $150 \mu \mathrm{m}$ ). Axons arborizing in $4 \mathrm{C} \beta$ send occasional collateral branches into adjacent $4 \mathrm{C} \alpha$ but not into any other lamina. Since layer $4 \mathrm{C} \beta$ is known to receive its primary afferents from the parvocellular laminae of the LGN (Hubel and Wiesel, 1972), it is believed that these axons represent parvocellular afferents. This conclusion is supported by results from our intra-axonal recordings and electrophoretic injections with HRP (see Figs. 9A, 12, 13, and 14). 


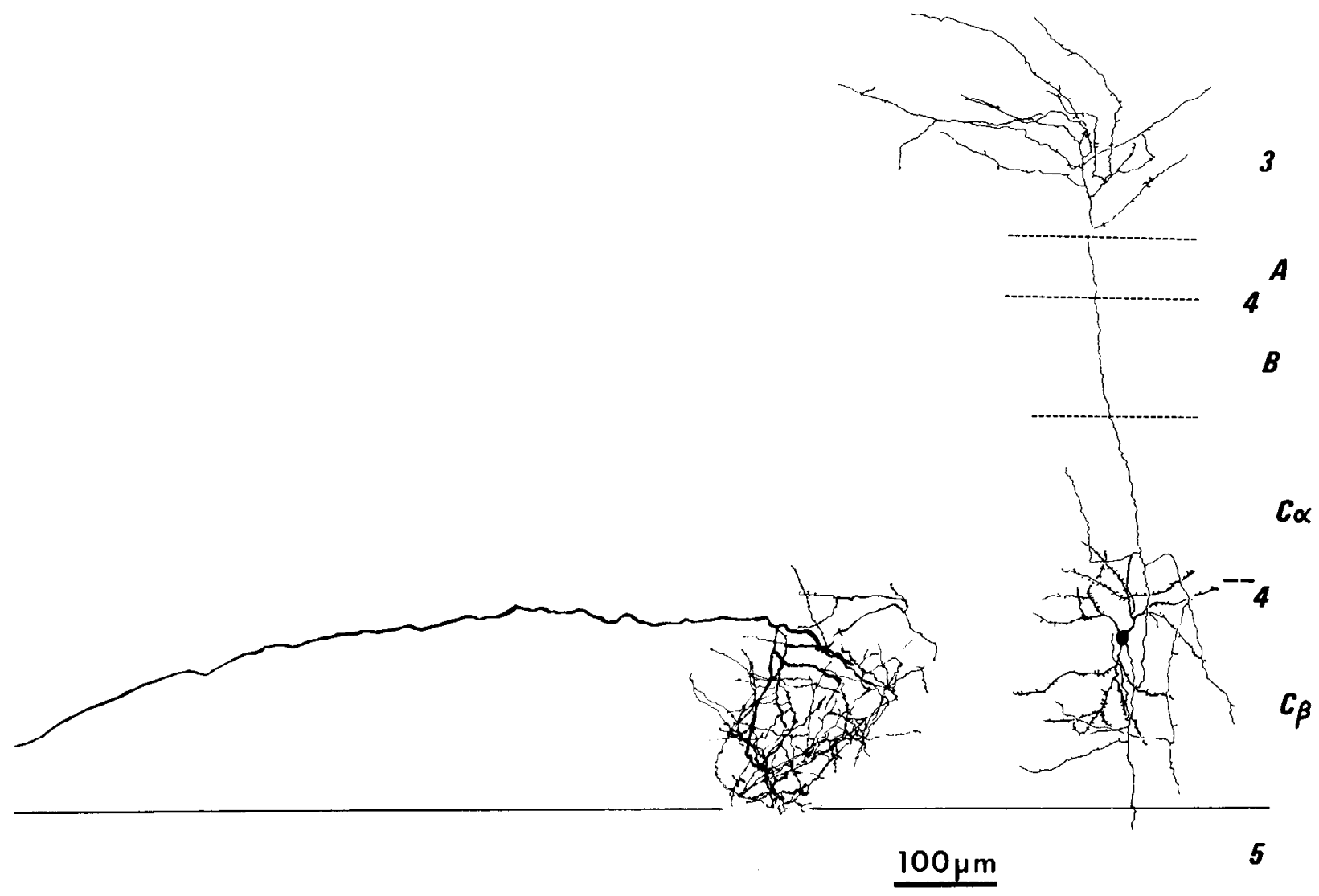

Figure 11. Drawing of an afferent axon that has been filled with HRP from a white matter injection. This axon is typical of those found to arborize in $4 \mathrm{C} \beta$ in that it rises obliquely through the grey matter and travels horizontally (800 $\mu \mathrm{m})$ for some distance before finally ending in a tight terminal cluster of boutons. The long preterminal trajectory in grey matter might be expected from developmental processes of axon segregation that are known to occur. A Golgi-impregnated spiny $4 \mathrm{C} \beta$ stellate cell is illustrated on the right at the same scale so that the size of its dendritic arborization can be compared with the terminal field of the afferent axon. These cells are believed to receive the bulk of the parvocellular geniculate input. It should not be assumed, however, that each axon impinges upon a single cell simply because the dendrites and axonal domains are similar in size; there are many more neurons in layer $4 \mathrm{C}$ than there are entering LGN axons (see the text).

with color-opponent LGN-like receptive fields (type I of Wiesel and Hubel, 1966) and specific terminations in $4 \mathrm{C} \beta$. One of these had a receptive field with a $0.3^{\circ}$, circular red-ON center, green-OFF surround, located at $6^{\circ}$ eccentricity. Although the axon preterminal trunks were well labeled, too little HRP found its way into the terminal boutons to permit a complete reconstruction. As shown in the reconstruction of Figure 12, however, it was possible to reconstruct most afferent branches. These converge on a terminal zone that is well restricted and very similar to those of $4 \mathrm{C} \beta$ axons already described (obtained following bulk injections of HRP into the white matter).

A second well filled axon, whose receptive field had a color-opponent blue-ON center, (red + green)-OFF surround was recovered from another animal (Fig. 13). This axon, which was recovered from the opercular surface of striate cortex, had a $0.4^{\circ}$ receptive field center located at an eccentricity of $7^{\circ}$. In common with other $4 \mathrm{C} \beta$ axons, the trunk traveled for long distances through the neuropil before finally entering into its terminal zone. Unlike previously described $4 \mathrm{C} \beta$ processes, however, this axon made a portion of its lateral journey at a very high level (above lamina $4 \mathrm{~A}$ ) before descending suddenly into $4 \mathrm{C} \beta$.
A computer reconstruction allowed us to rotate it about the $\mathrm{X}$-axis and thereby gain further insight into the distribution of the terminal zone (Fig. 14). Seen from the pial surface (bottom of Fig. 14) this axon covers a tangential area of $0.067(1 / 15) \mathrm{mm}^{2}$, or one-sixth that covered by the $4 \mathrm{C} \alpha$ axon of Figure 6 . We counted 499 beaded profiles; and, as can be seen in Figure 14, the density is greatest in the center so that most occur within a radius of $90 \mu \mathrm{m}$. At the level of layer $5 \mathrm{~A}$, fine processes emerge from the main trunk and travel toward the terminal field in $4 \mathrm{C} \beta$, staying high in lamina 5 ; but no arbors are seen in other laminae. As further examples of intracellularly filled axons are obtained, it is possible that we may find ones with principal arbors in $4 \mathrm{C} \beta$ and collateral projections to the deeper layers; however, the present material provides no evidence for such projections.

Axons terminating in layer $4 A$. Four bulk filled axons were observed terminating in layer $4 \mathrm{~A}$. These appear in Figures 15 and 16. Like axons ending in layer $4 \mathrm{C} \beta, 4 \mathrm{~A}$ axons tend to travel horizontally for some distance through the grey matter before terminating in a relatively circumscribed clump of boutons. Some of the terminations reach higher, as fine, vertically oriented, rising processes, into lamina 2-3 (Fig. 16A). Computer recon- 


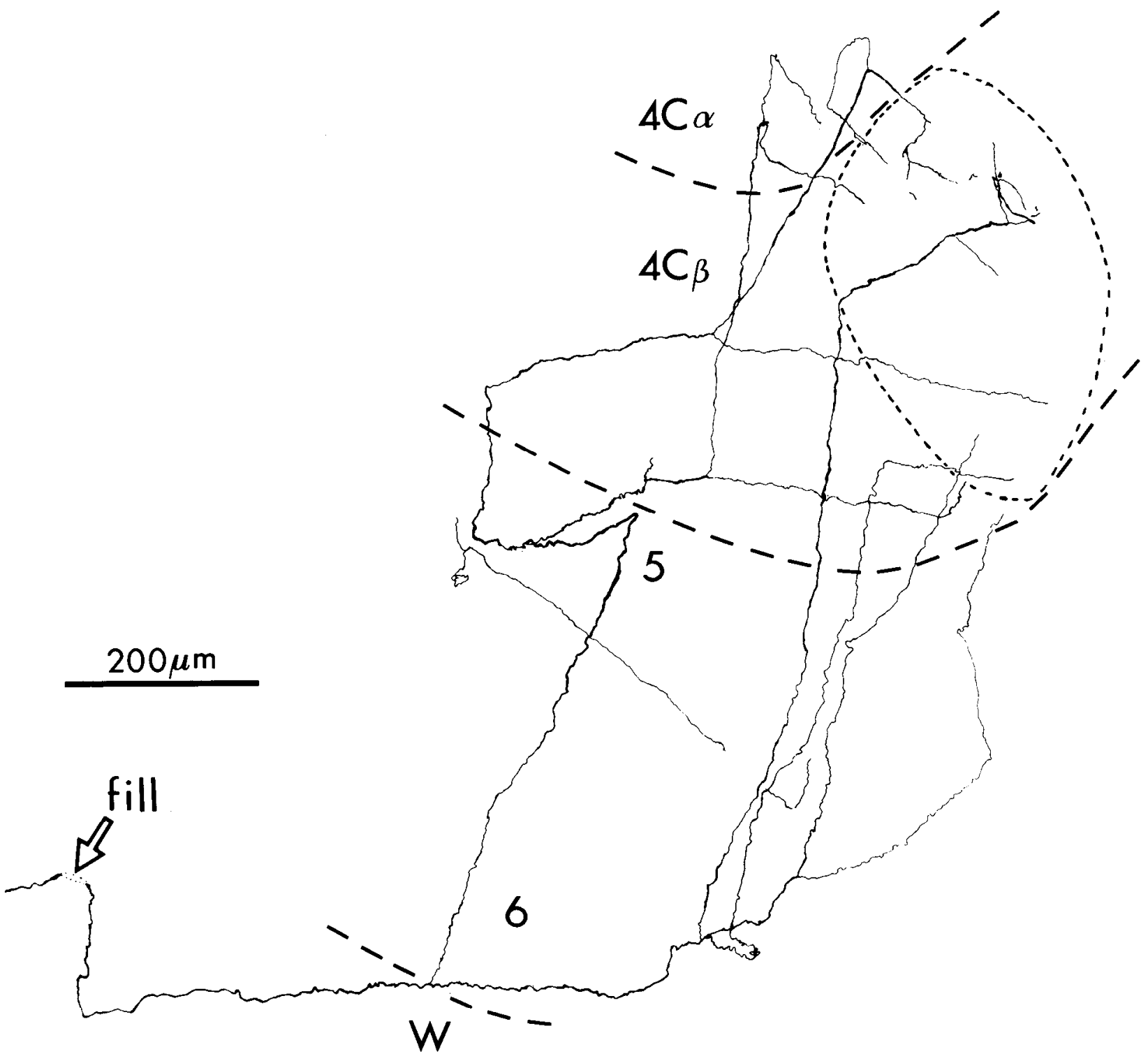

Figure 12. Reconstruction of an axon that has been intracellularly filled with HRP. Physiologically, this axon had a type 1 (Wiesel and Hubel, 1966) color-opponent receptive field with a red-ON center and a green-OFF surround. Accordingly, it most probably derives from a cell in one of the parvocellular laminae of the LGN. The receptive field center was approximately $0.3^{\circ}$ in diameter at a visual field eccentricity of $6^{\circ}$. The HRP filling of this fine axon was unfortunately incomplete, especially in its terminal field, which was found to contain faintly filled boutons within the area marked by the fine broken line. Inasmuch as its arborization began in $4 \mathrm{C} \beta$, however, its characteristics, both anatomical and physiological, are of special interest. Nearly all of the preterminal trunks enter a common, restricted area of $4 \mathrm{C} \beta$, even though they reach this limited region by very different routes (not evident in this reconstruction which was made from highly tangential serial sections). This axon, together with that shown in Figure 13, provides some assurance that the axons we had observed previously, with arborizations in $4 \mathrm{C} \beta$, indeed arise from the parvocellular laminae of the LGN.

struction, followed by a $90^{\circ}$ rotation about the X-axis, reveals the tangential view, shown in Figure $16 C$, with characteristic circular, terminal-poor regions, approximately $80 \mu \mathrm{m}$ in diameter, lying within the terminal field and having a center to center separation of about $100 \mu \mathrm{m}$. This honeycomb appearance has also been observed for tangential sections of $4 \mathrm{~A}$ following orthograde transport of tritiated label from the LGN (Hendrickson et al., 1978). We counted 764 boutons for this axon which, discounting the lacunae, were observed to fill a tangential area of $0.058 \mathrm{~mm}^{2}$-an area that is slightly less than that covered by a single $4 \mathrm{C} \beta$ axon. Because there are more boutons, though, the density per unit area is greater (13.2 $\times 10^{3}$ boutons $/ \mathrm{mm}^{2}$ ). These axons have not yet been physiologically identified or intracellularly filled.

Axons terminating in layer 1. Following bulk injections of HRP into the white matter, we frequently observed a tangle of very fine filaments in layer 1 . Because this layer is known to receive inputs from sources besides the thalamus, and because there really is very little chance of extricating a single process from the tangle, especially through serial sections, we did not attempt any reconstructions.

During our subsequent intracellular recordings, how- 
3

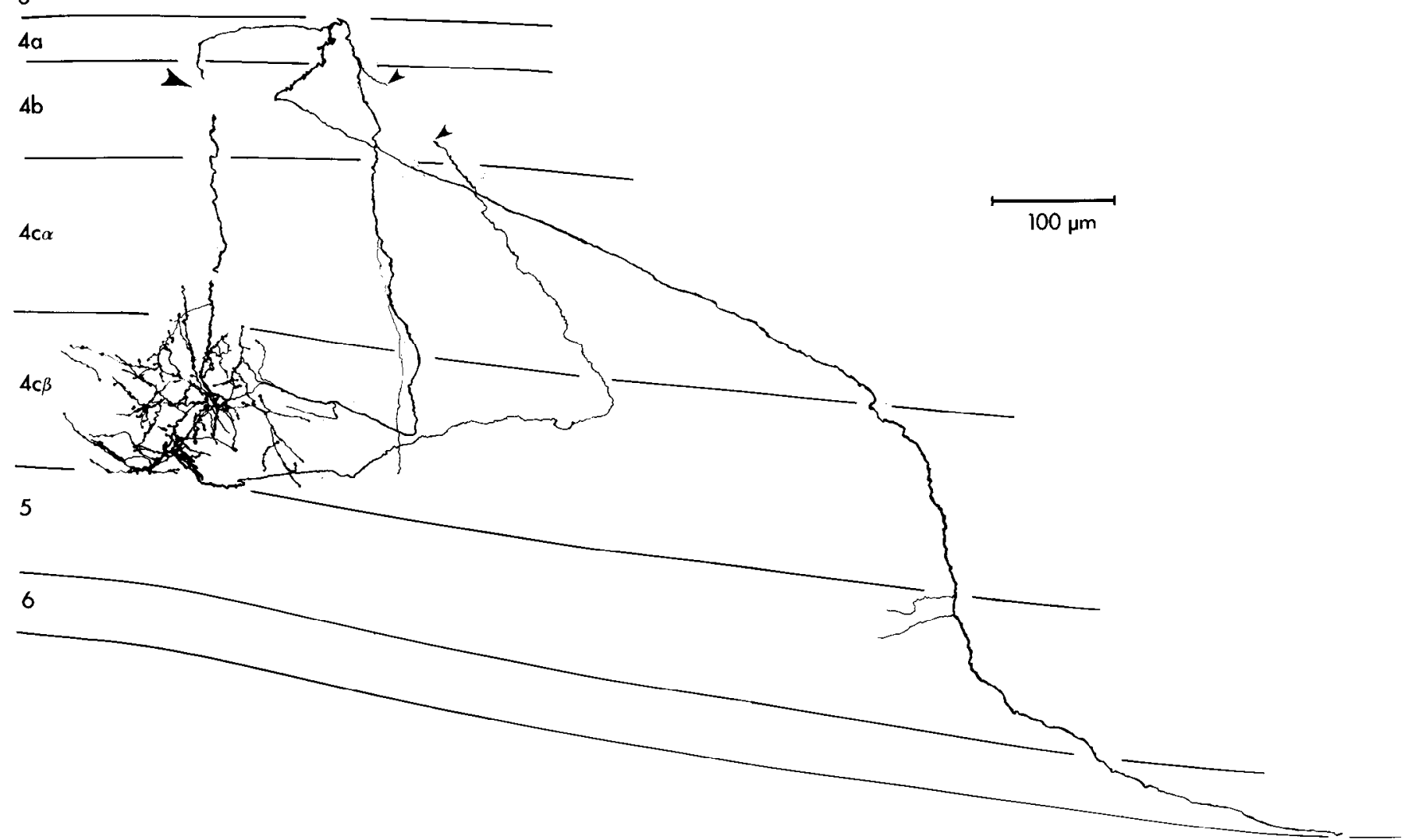

Figure 13. Reconstruction of an axon with terminal arbor in lamina $4 \mathrm{C} \beta$ that was filled intracellularly with HRP at a point that was later found to lie high in the cortical grey matter, approximately at the level of lamina 4B (large arrowhead). Physiologically, this axon displayed a blue-ON center and a (red + green)-OFF surround. The center region was approximately $0.4^{\circ}$ in diameter and was located at an eccentricity of $7^{\circ}$. From the reconstruction, one can follow the extended and highly asymmetrical course of this axon through the cortical grey matter; the main axon trunk actually travels in or above layer $4 \mathrm{~A}$ before descending to its terminal zone in lamina $4 \mathrm{C} \beta$. The reconstruction of this axon with a computerized microscope (see Figure 14) also shows the trajectories of the preterminal trunks that converge from different directions upon a circular terminal zone. Fine, poorly filled processes leave the main trunk at the top of lamina 5; but, because these do not show boutons, they are presumed also to travel to the same terminal field. The correlation of physiological properties and terminal arbor location strongly supports the conchusion that axons of this terminal morphology derive from the parvocellular laminae of the LGN. The gap in the process between the small arrowheads was due to the heavy staining of a large blood vessel in the tissue. The continuity of the two processes is certain, however, because this axon was the only HRP-filled process in the vicinity.

ever, we penetrated one axon which had a receptive field with a surprisingly large blue-ON center. The perimeter of this axon's receptive field center subtended $0.75^{\circ}$ at an eccentricity in the visual field of $8^{\circ}$ where the centers of other thalamic afferents averaged only about $0.25^{\circ}$. The center gave a brisk, sustained discharge to the onset of a blue stimulus and no response (or a minor one at best) to red, green, yellow, or white stimuli. No surround was evident when the axon was tested with large disks of any color. Accordingly, the axon probably was not of type I (Wiesel and Hubel, 1966) but could have been of type II. A type II LGN axon would have been expected to give an off response to green light (which we did not sce). However, the response is often quite weak (Wiesel and Hubel, 1966), and it is conceivable that we missed it. The fact that the cell did not respond well (or at all) to white or yellow light indicates that there must have been some sort of color-selective antagonism associated with longer wavelengths. Inasmuch as there is no other known source of nonoriented, color-selective cells with striate projections, we believe that this process derived from the parvocelluar laminae of the LGN.
Upon reconstruction (Fig. 17) the axon was found to arborize extensively in layers 1 and upper 6 . All processes possessed an extremely fine and delicate appearance (Fig. $3 B$ ) and spread over large distances (greater than $2 \mathrm{~mm}$ ). The amount of spread is, in fact, so great that the most distal parts are not well labeled. Consequently, it is possible that the total spread is even greater than we estimate. Nevertheless, from those parts that we have reconstructed, one can conclude that this axon arborizes in at least four separate patches, each about $300 \mu \mathrm{m}$ in width, that extend over a total distance of at least $2 \mathrm{~mm}$ and that could correspond to one set of ocular dominance bands.

Relations with ocular dominance columns. When an axon arborizes in long stripes or in multiple $300-\mu \mathrm{m}$ patches, it is tempting to conclude that the patches in fact correspond to the ocular dominance bands that are seen with transneuronal autoradiography (Hubel and Wiesel, 1977). In one animal we tested this possibility by injecting an eye with tritiated proline and allowing 2 weeks for transneuronal transport before filling axons. After the axon appearing in Figure 4 had been recon- 

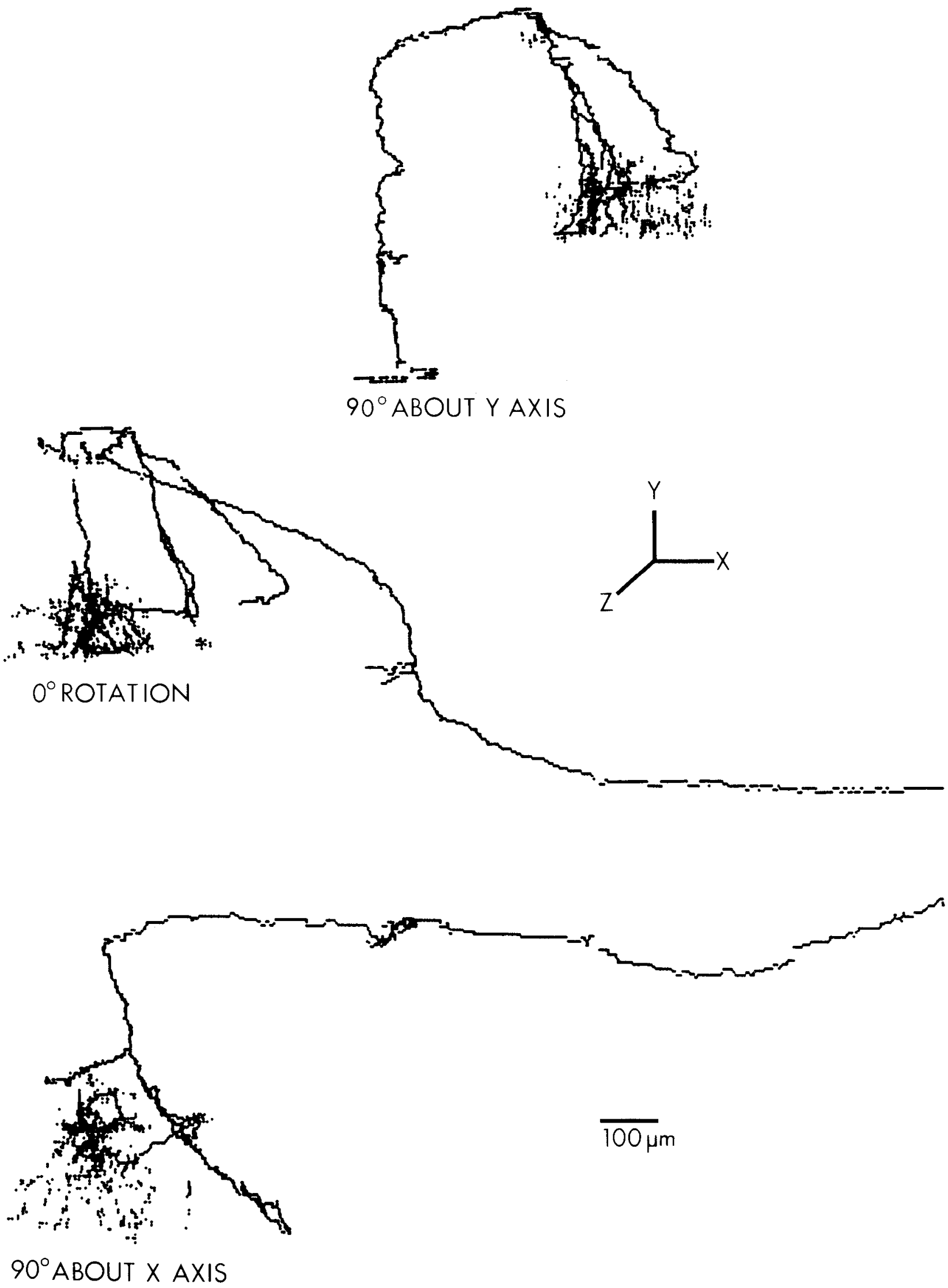

Figure 14. In order to gain a better appreciation for the tangential spread of the axon shown in Figure 13, we reconstructed major trunks (solid lines) and boutons (dots) in three dimensions with the aid of a computer microscope (see "Materials and Methods"). From these, it is possible to rotate the axon about different axes. The digitized rendition of the axon appearing in Figure 13 is shown at the center. At the top, this same axon is seen rotated $90^{\circ}$ about the Y-axis; at the bottom, it appears rotated $90^{\circ}$ about the $\mathrm{X}$-axis, as if viewed from the pial surface. 


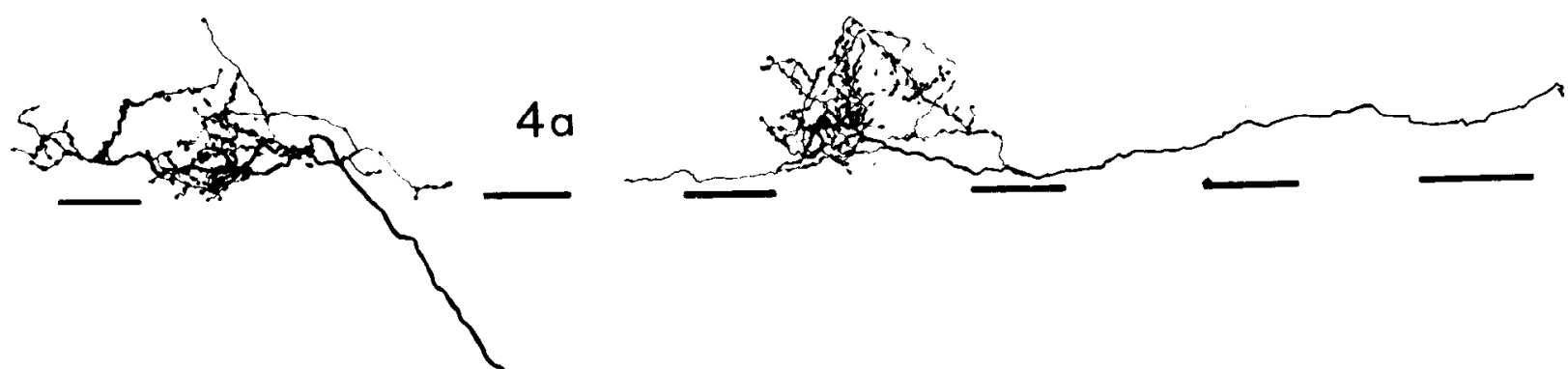

$4 b$

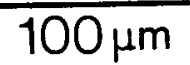

Figure 15. Drawings of two axons whose primary arborizations are in lamina 4A (filled by HRP injection into the white matter). These processes have relatively circumscribed fields which extend no more than $150 \mu \mathrm{m}$ laterally. Neither were observed to have collaterals in other cortical laminae.

structed, we pressed the de-coverslipped sections against LKB tritium film for 3 months in order to localize the ocular dominance bands. A montage of layer $4 \mathrm{C}$, taken from 50 serial sections that were cut in the coronal plane, appears in Figure 18A. From this reconstruction, ocular dominance columns can be seen to run in the direction expected (LeVay et al., 1975) for this part of the cortex (roof of the calcarine fissure). The projection of the contralateral oplic disk appears at the right. In Figure $18 B$ we have added the boundaries of ocular dominance bands, and in Figure $18 C$, where these boundaries are displayed alone at higher magnification, we have added shading to the regions that were observed to contain filled terminals belonging to the axon of Figure 4. From this figure one can see that the three patches of terminals appearing in Figure 4 in fact coincide with one set of ocular dominance bands. However, from this reconstruc- tion and from the axon shown in Figure $6 B$, we know that axon trunks run through and even give off a few scattered boutons in the alternate bands. Conceivably, such intrusions may explain the higher than background activity, following transneuronal transport and autoradiography, that characterizes the interband zones.

\section{Discussion}

These studies offer new insights into the transfer of visual information from neurons of the LGN to those of striate cortex. The terminations of individual axons are consistent with and provide a substructure for the observed parcellation of inputs into different vertical and horizontal zones. In general, it can be said that axons with terminations in different cortical laminae are highly stereotyped in appearance. Terminations in layer $4 \mathrm{C} \beta$, for example, occur as discrete, single clumps, whereas 


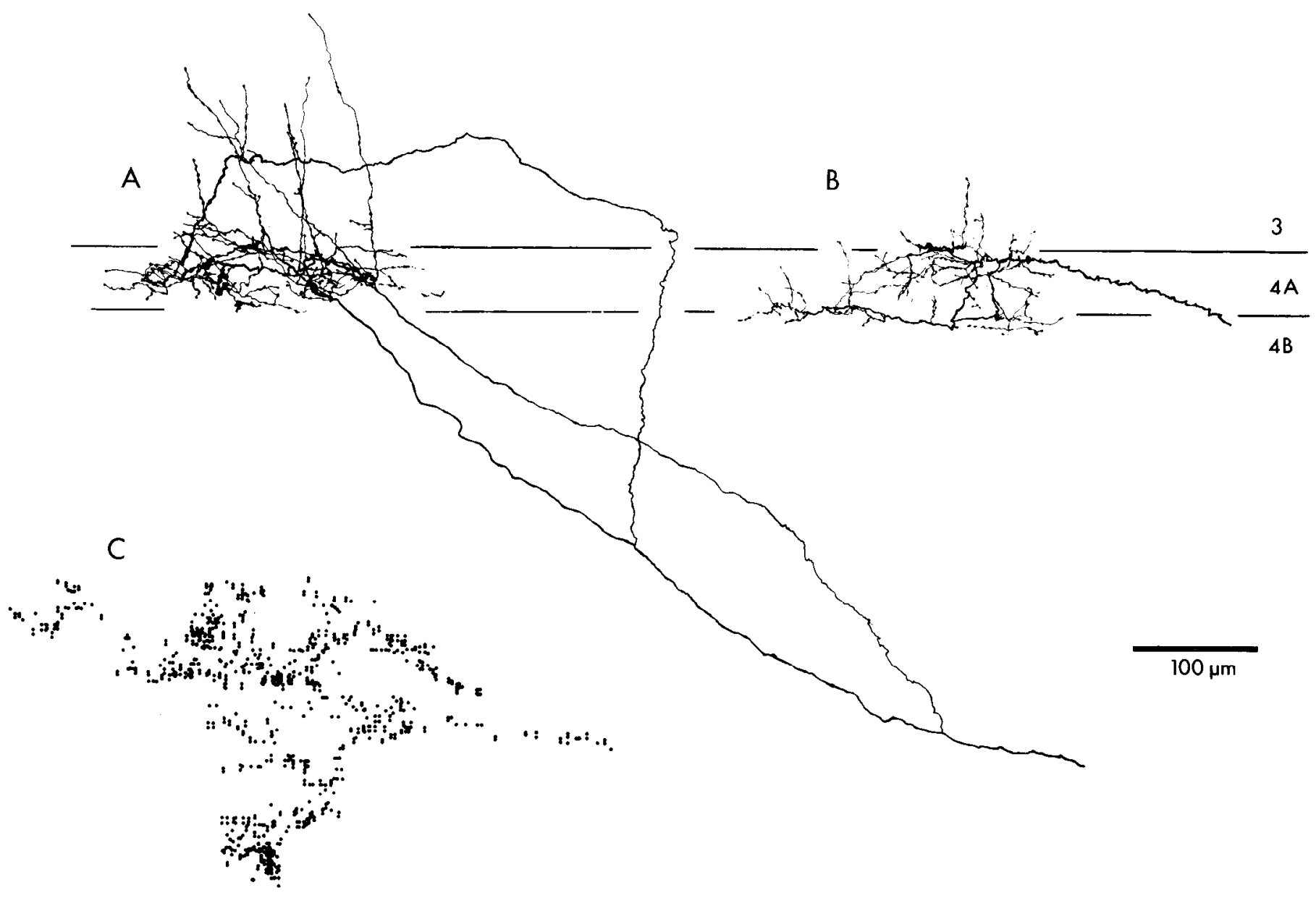

Rotated 90 Degrees About X Axis

Figure 16. Two axons ( $A$ and $B$ ) with terminal arbors in lamina 4A. Axon $A$, in particular, shows fine, rising, beaded, terminal processes which extend into layers 3 and lower 2 . No terminal processes were seen to arise from the axon trunks passing through the deep layers. $C$, The terminal bouton distribution of axon $A$ was mapped using a computerized microscope which made it possible to rotate the image by $90^{\circ}$ about the $\mathrm{X}$-axis so that it could be viewed en face. The boutons are found to cluster as walls around empty lacunae roughly $100 \mu \mathrm{m}$ from center to center. More boutons appear on this map than in the drawing in $A$ because $A$ only includes processes that could be traced to the parent trunk. The distribution in $C$, on the other hand, includes boutons that appear to belong to this axon, even though the fine intervening processes were not well filled. The scale is common to $A, B$, and $C$.

those ending in $4 \mathrm{C} \alpha$ cover larger areas and can end in multiple patches that resemble parts of ocular dominance columns. Axons terminating in $4 \mathrm{~A}$ are about as discrete as those found terminating in $4 \mathrm{C} \beta$ and, when viewed from the pial surface, they have the honeycomb appearance that has already been described following autoradiographic experiments. One axon, found terminating in layer 1 , had an extremely wide terminal distribution, along with a correspondingly large receptive field. And projections to layer 6 were seen only as collaterals of more major projections to other laminae.

For many axons, the terminals do not reside entirely within one subdivision. For example, axons with primary terminations in $4 \mathrm{C} \beta$ frequently send a few beaded processes into the lower part of $4 \mathrm{C} \alpha$, and axons ending within the borders of $4 \mathrm{C} \alpha$ send occasional processes below into $4 \mathrm{C} \beta$. This is not to say, however, that there is necessarily any functional overlap because a small amount of overlap correlates with the lack of strict den- dritic segregation at the border between laminae $4 \mathrm{C} \alpha$ and $4 \mathrm{C} \beta$ (see Lund, 1973). While the boundary of $4 \mathrm{C} \beta$ with lamina 5A always appears quite sharply defined (in terms of thalamic axon distributions shown by transneuronal autoradiography), we do not know if there is necessarily a sharp boundary between $4 \mathrm{C} \beta$ and $4 \mathrm{C} \alpha$ in any anatomical or functional terms. The scatter of axon collaterals (and dendrites; S. L. Mates and J. S. Lund, manuscript in preparation) across the hypothetical boundary suggests, at least, that a steep anatomical gradient exists between the $\alpha$ and the $\beta$ subdivisions.

Axons with terminal fields above layer $4 \mathrm{C}$, in layers 1 , $2-3$, and $4 \mathrm{~A}$, never occurred as collaterals of $4 \mathrm{C}$ arborizations. Terminals in the upper half of layer 6 , on the other hand, were only observed (in one instance) as collaterals to a larger projection in layer 1 . Hence, based on the current study, there appear to be at least three major populations of parvocellular axons: (1) those providing input to layer $4 \mathrm{C} \beta$, (2) those projecting into layer 


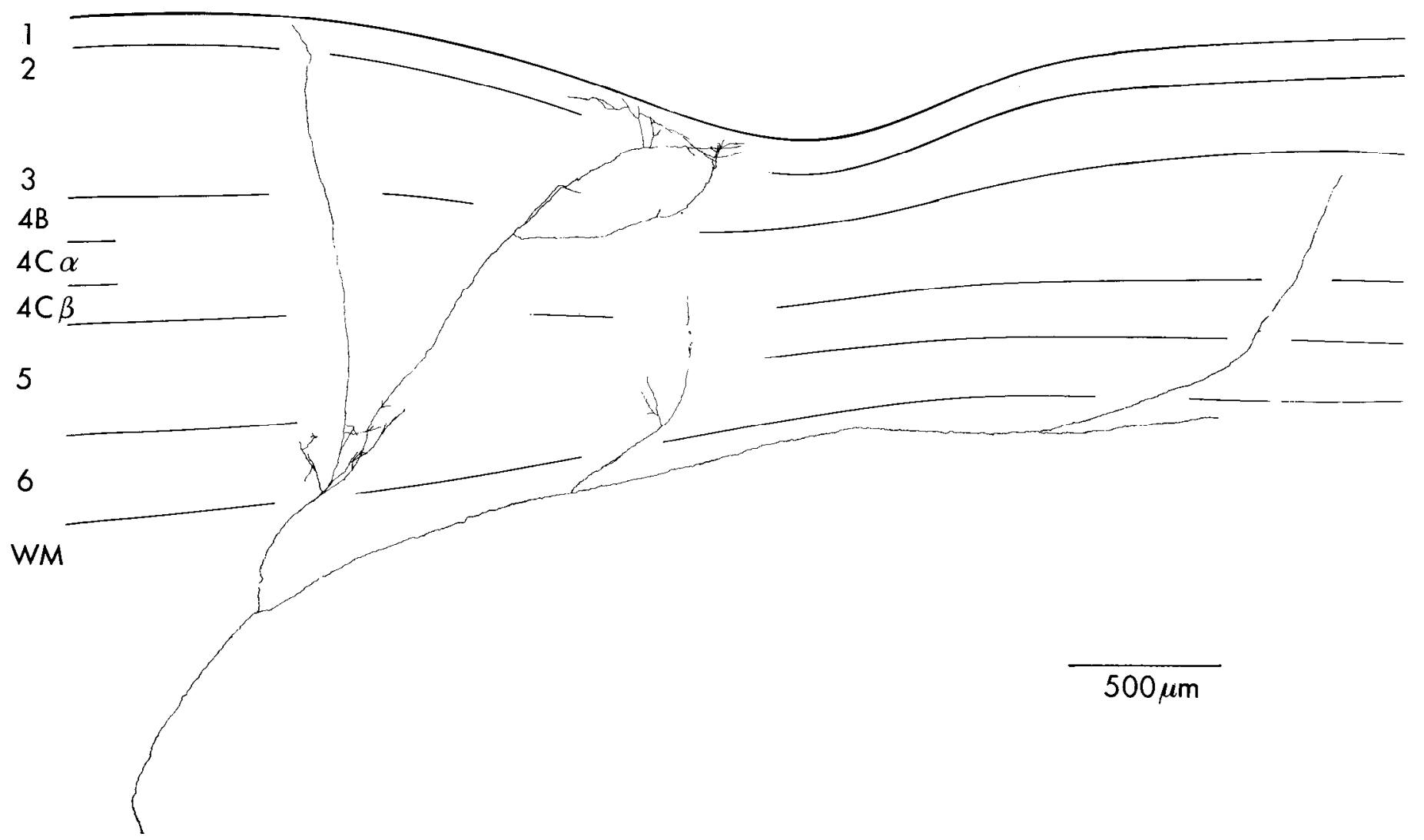

Figure 17. This layer 1 axon was recovered following the iontophoretic filling of a process that was intracellularly recorded and found to have a large $\left(0.75^{\circ}\right.$ at an eccentricity of only $\left.6^{\circ}\right)$ blue-ON center receptive field. No surround was apparent. In addition to the wide ranging terminals in layer 1 , seen emerging from the best labeled ascending trunk, this axon was also observed to give off collaterals in layer 6A. A photograph of the exceedingly fine layer 1 terminals appears in Figure $3 B$. From the reconstruction it appears that this axon probably arborizes in four scparate patches (covering at least $2 \mathrm{~mm}$ ) that could correspond to the ocular dominance of one eye. Only one of these patches filled well enough to be completely reconstructed.

$4 \mathrm{~A}$, and (3) those distributing to laminae 1 and $6 \mathrm{~A}$. Inasmuch as some of the $4 \mathrm{~A}$ arborizations were observed to send fine ascending collaterals into layer $2-3$, it is possible that some of these may have come from the intercalated LGN laminae instead of from parvocellular laminae (Fitzpatrick et al., 1983). With respect to the magnocellular LGN laminae, there may be two types of afferent: those (the majority of our sample) which arborize in the lower two-thirds of $4 \mathrm{C} \alpha$, with minor or no collateral input to lower 6 , and those (one intracellularly filled axon in our sample) which arborize in the upper half of layer $4 \mathrm{C} \alpha$ and which have extensive collaterals in layer 6 below. At this point it is unclear whether the second type represents a distinct class or part of a continuum since, on the basis of our physiological tests, it appears no different from other magnocellular-like axons that were later found to arborize in the deep part of $4 \mathrm{C} \alpha$. Further experiments will be needed to resolve this issue because it is conceivable that had we tested for other physiological properties, such as the presence or absence of linear summation, this axon might have fallen into a separate physiological class (Shapley et al., 1981).

The fact that the terminal fields of individual axons arborizing in $4 \mathrm{C} \alpha$ cover about 6 times as much territory as ones found arborizing in $4 \mathrm{C} \beta$ is not surprising in view of their presumed origin from cells in the magno- and parvocellular LGN laminae. Although parvo- and mag- nocellular LGN laminae must each project to equally large areas of striate cortex, they differ greatly (by a factor of 6 ) in the number of available cells. In fact, the ratio of cells in the parvo- and magnocellular LGN laminae is not a constant but varies with eccentricity-the ratio is greater for central projections than it is for more peripheral ones (D. C. Van Essen, personal communication). Accordingly, it will be interesting to see if the ratio of areas covered by single $4 \mathrm{C} \alpha$ and $4 \mathrm{C} \beta$ afferents also varies with eccentricity.

The terminal portions of all studied axons possess a serial beaded appearance. Previous electron microscopical work (Winfield et al., 1981) has shown that beads such as these typify thalamic afferents to macaque striate cortex and give rise to one or more "en passant" (Gray, 1959; type I) synaptic contacts. In this respect, our HRPfilled axons resemble those previously described by others (Ferster and LeVay, 1978; Gilbert and Wiesel, 1979) for the cat, although the ones we have described are more discrete in their terminal fields, perhaps in agreement with the monkey's greater visual acuity. They differ, however, from the Golgi-impregnated single side spine-bearing axons suggested by Valverde (1971) and by Lund (1973) as thalamic axons. The axons described by these investigators, which start to impregnate at the top of lamina 5, fall into two groups: one with primary arbors in $4 \mathrm{C} \beta$ and secondary ones in layer $4 \mathrm{~A}$, and another with 
single arborizations in $4 \mathrm{C} \alpha$. Because the current study did not fill such axons and shows that axons labeled from the white matter (from intra-axonal or bulk injections of HRP) are beaded in morphology with very different distributions, the Golgi-impregnated axons must arise from some other source. Their very symmetrical distribution around the rising axon trunk (see below with regard to the asymmetrical spread of LGN afferents) and their failure to fill after white matter injections of HRP suggest that they may arise instead from within the cortex; for example, from the pyramidal neurons of layer 6. In young animals, these cells have been shown to contribute recurrent axons with side spines and laminar distributions very similar to the previously proposed thalamic afferents (Lund and Boothe, 1975; Lund et al., 1977). ${ }^{4}$ In Golgi impregnations of adult cortex, on the other hand, portions of beaded axons resembling those filled with HRP in the present study occur regularly in laminae $4 \mathrm{C}$ and $4 \mathrm{~A}$, but these cannot be reconstructed, most probably because myelin has prevented full impregnation.

Evidence for the LGN as the site of origin. In the case of our intracellularly recorded axons, the evidence that they emanate from the LGN rests on our observation that their receptive field properties were identical to those of LGN neurons and that they end in laminae already documented as terminal sites for LGN axons (Hubel and Wiesel, 1972, 1977; Hendrickson et al., 1978; Fitzpatrick et al., 1983). For axons filled from white matter injections of HRP, our conclusion that they derive from the LGN is based on a number of mutually supportive observations. In the case of axons with arborizations in $4 \mathrm{C} \alpha$ and $4 \mathrm{C} \beta$, this conclusion is supported by the strong morphological similarity between our microinjection-filled samples and those derived from intracellular filling. In the case of our $4 \mathrm{~A}$ arborizations, this conclusion is likewise supported by the strong similarity in appearance between our axons viewed en face and the honeycombed appearance that characterizes thalamic inputs to this lamina (Hendrickson et al., 1978). For the axons we have described with arborizations in $4 \mathrm{~A}$ and $4 \mathrm{C}$ it should also be pointed out that their serially beaded morphology resembles that of the profiles identified by Winfield et al. (1981) as characteristic of LGN afferents.

Our microinjection-filled samples may also be identified with the LGN on the basis of their spatial distributions within striate cortex. As noted earlier, all examples of $4 \mathrm{C}$ afferents are characterized by dense terminal fields that are circumscribed and largely limited in their vertical spreads to either the upper or the lower divisions of 4C. In the case of $4 \mathrm{C} \beta$ the terminations are extremely discrete, extending no further than $200 \mu \mathrm{m}$ in any lateral direction. In terms of the known cortical magnification (Hubel and Freeman, 1977), these distances correspond, at any particular eccentricity, to the approximate size of

\footnotetext{
${ }^{4}$ In Golgi impregnations of adult animals, the silver impregnation of recurrent initial axon segments ceases shortly after the processes emerge from layer 6 pyramids, as a consequence of myelination. Myelin forming a barrier to silver impregnation also underlies the finding that in Golgi material from adult animals it is common to impregnate axon terminal fields but not the preterminal trunks.
}

an LGN receptive field. Furthermore, the greater spreads of $4 \mathrm{C} \alpha$ axons coincide with the fact that cells in the magnocellular LGN laminae have larger receptive field centers than those in the parvocellular laminae (Sherman et al., 1976; G. G. Blasdel, D. Fitzpatrick, and J. S. Lund, manuscript in preparation).

In contrast to these strict and precise patterns of termination, afferents from nongeniculate sources either (1) do not project to the appropriate LGN recipient laminae, or (2) they spread into adjacent laminae that are known not to receive an LGN input, or (3) they relate to striate cortex in a diffuse fashion that is inconsistent with precise topography. For example, afferents from pulvinar and extrastriate cortex do not end in layers $4 \mathrm{~A}$ or 4C (Benevento et al., 1975; Ogren and Hendrickson, 1976; Spatz, 1977; Tigges et al., 1977; Rockland and Pandya, 1981). While the claustrum projects in a topographic fashion to geniculo-recipient laminae, there is no evidence for the precise laminar segregation that characterizes LGN inputs (Carey et al., 1980; LeVay and Sherk, 1981). And the numerous other small nuclei that have known projections to striate cortex (e.g., locus ceruleus, nucleus dorsalis raphe, etc.; see study and review of Tigges et al., 1982) relate to striate cortex in too diffuse a fashion for their afferents to resemble those we have described.

Asymmetry of axon preterminal and terminal regions. As noted earlier, filled axons in layer $4 \mathrm{C}$ display a marked tendency to rise obliquely through the grey matter and travel variable distances along the $\alpha / \beta$ boundary before forming their terminal arbors. From a developmental point of view, the asymmetrical spread of these axons corresponds well with recently suggested mechanisms of axon sorting. From the work of LeVay et al. (1980) it is known that projections into layer $4 \mathrm{C}$ form in an initially diffuse fashion; before 5 or 6 weeks of age the ocular dominance bands-a prominent feature of the adult cortex-exist only as a statistical fluctuation in terminal density (Rakic, 1977). As the animal matures, LGN terminals corresponding to each eye gradually segregate until they come to occupy alternating segments of layer $4 \mathrm{C}$. Given this developmental sequence, it seems unlikely that a maturing axon, once it has segregated and established its terminal field, will retract and then re-enter the grey matter along a more direct route. Accordingly, the expected developmental scheme should produce populations of axons with varyingly asymmetrical preterminal trunks-populations similar to the ones we have observed. In theory then, the maximum distance that these preterminal trunks are found to travel (on the order of $800 \mu \mathrm{m}$ ) should correspond to one-half the spread of an individual arbor in the neonatal animal. The overall degree of asymmetry would, of course, be magnified and probably distorted by increases in the area of striate cortex during maturation.

The fact that axons terminating in $4 \mathrm{C} \alpha$ distribute so much more widely than those ending in $4 \mathrm{C} \beta$ has an interesting consequence for these two classes of terminals. Although segregation of ocular dominance stripes in the $\alpha$ division occurs even within the domain of single axon arbors, segregation in the $\beta$ division must occur between populations of afferents. It is evident, therefore, 

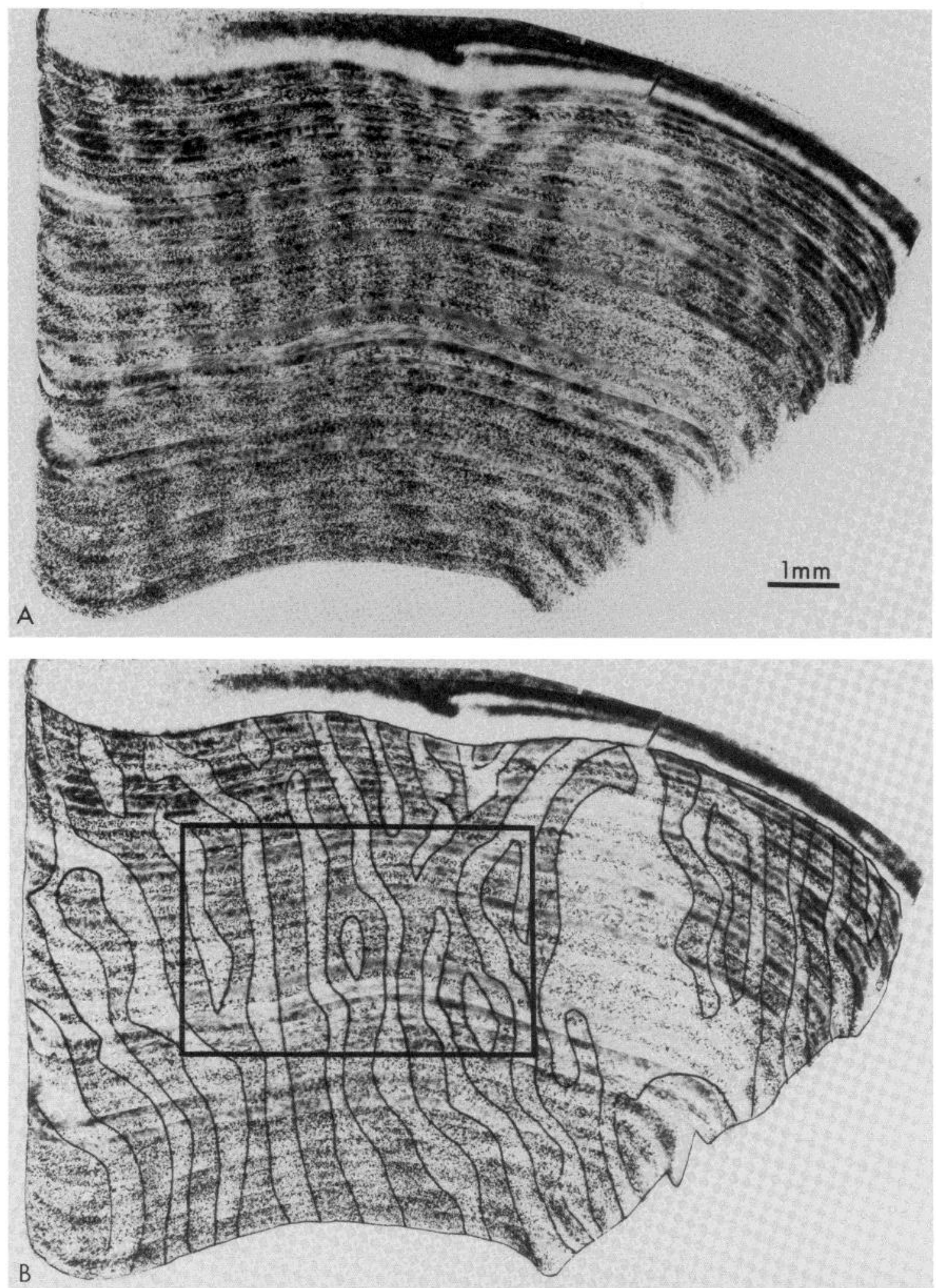

Figure 18. A, This montage was created by assembling cut-out strips of lamina $4 \mathrm{C}$ autoradiograms. The serial sections that were used contain the $4 \mathrm{C} \alpha$ axon appearing in Figure 4 . Because the monkey had received an injection of tritiated proline ( $3 \mathrm{mCi})$ in the right eye, it was possible, following reconstruction of the axon, to decoverslip the sections and press them against LKB tritium film to reveal the pattern of ocular dominance bands. Because the autoradiograms were photographed under brightfield illumination, regions containing radioactivity (and hence corresponding to LGN afferents of the right, injected eye) appear dark. The unlabeled projection of the contralateral optic disk appears prominently at the right. Due to the variable thicknesses of the layer $4 \mathrm{C}$ regions that were needed to create a continuous montage, this reconstruction is distorted vertically (by a factor of almost $2: 1$; accordingly, the 1-mm scale refers only to the horizontal axis. $B$, In this photograph, the montage of $A$ has been overlayed with an acetate sheet depicting our estimation of the ocular dominance boundaries. The region within the square is shown enlarged in C. $C$, An enlarged view of the outlined region in $B$ which contains the terminal $4 \mathrm{C}$ arborizations of the axon shown in Figure 4. As can be seen from this enlargement, the three patches of terminal boutons are restricted largely to one set of ocular dominance bands (belonging to the injected right eye). 


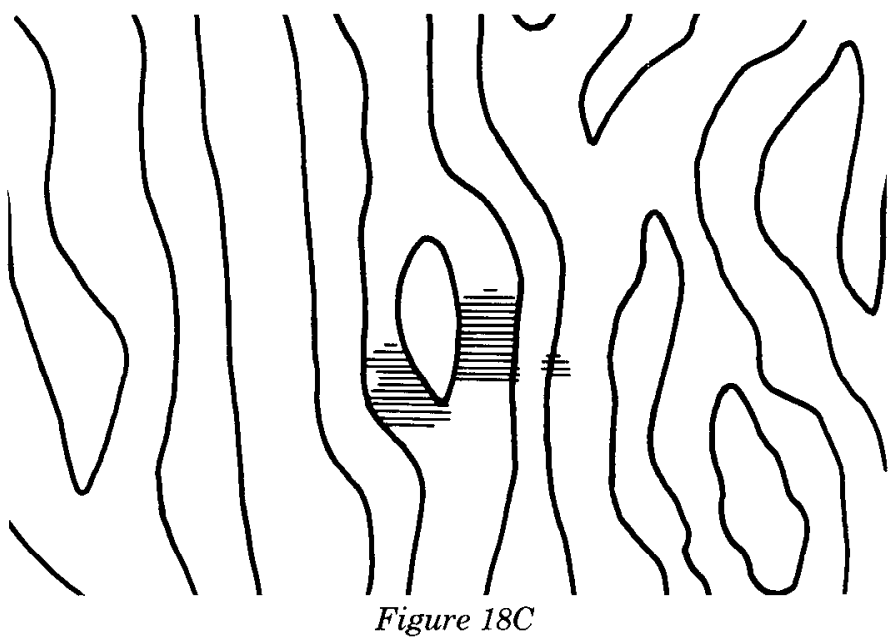

that there are at least two constraints acting on segregating populations of terminals in the young animal: (1) segregation according to ocular dominance and (2) segregation according to retinotopic position. Because the periodicity of ocular dominance bands $(400 \mu \mathrm{m})$ corresponds more closely to the greater spread of $\alpha$ axons, it would seem that ocular dominance groups are determined initially by competition within this group. Once these are formed in $4 \mathrm{C} \alpha$, the local topography for $4 \mathrm{C} \beta$ might then be sorted out among the finer grained parvocellular inputs, within the borders of the appropriate ocular dominance "column." If so, this sequence could explain why the plasticity of $\alpha$ afferents wains at an carlicr age than that of the $\beta$ afferents (LeVay et al., 1980).

Comparison with the cat. In their earlier work on the arborizations of afferent axons in cat striate cortex, Ferster and LeVay (1978) observed large arborizations of serially beaded processes. Those ending in layer $4 \mathrm{C}$, like our $4 \mathrm{C} \beta$ axons, were observed to have the most discrete projections. Typically, these spread no more than $600 \mu \mathrm{m}$ laterally. The axons which they observed ending in layer $4 \mathrm{AB}$, which might be thought of as corresponding to our $4 \mathrm{C} \alpha$ projections, spread over much larger distances (up to $2 \mathrm{~mm}$ ) and were found to terminate in three to five separate clumps. Although the same general beaded quality appears to characterize afferent thalamic axons in both the monkey and the cat, the terminal fields of axons we have observed in upper and lower $4 \mathrm{C}$ of the macaque monkey have been consistently smaller by a factor of 4 . This scaling factor, which is approximate, corresponds to the known visual acuity differences between the two species and seems to correlate with the fact that, at any particular eccentricity, receptive fields are many times larger for the cat than they are for the monkey (Hubel and Wiesel, 1968).

Implications for the retinotopic organization of layer $4 C$. Compared to most other mammals, the primary thalamic input zone (lamina 4C) of macaque striate cortex is unique. As first shown by Hubel and Wiesel (1968, 1974), the receptive fields of single cells recorded in layer $4 \mathrm{C}$ lack orientation selectivity and have the smallest dimensions of any that are found in striate cortex. They also have the least amount of positional scatter-an observation that suggests a rather precise retinotopic arrangement. In agreement with this suggestion, Hubel et al. (1974) subsequently found, by making highly tangential electrode penetrations, that the receptive field positions of successively recorded $4 \mathrm{C}$ cells shift in a predictable fashion for each advancement of the electrode tip. The organization is so strict that a precise map can be discerned easily within the width of a single ocular dominance "column;" that is, within about $400 \mu \mathrm{m}$.

Given such a precise representation, one naturally wonders how it might be achieved. The simplest explanation would be for the map to result directly from the geometry of terminating fibers. For this to be the case, one might expect afferent axons to arborize over small distances that are on a par with the dendritic spread of individual postsynaptic cells. For both $4 \mathrm{C} \alpha$ and $4 \mathrm{C} \beta$ this corresponds to a distance of about $180 \mu \mathrm{m}$. As we have seen from the preceding results and discussion (see Fig. 4 and 11), these conditions are met in $4 \mathrm{C}$ only by the parvocellular afferents to the $\beta$ subdivision. Afferents to $4 \mathrm{C} \alpha$, by contrast, spread over larger distances and frequently terminate in more than one ocular dominance band. Accordingly, on the basis of purely anatomical arguments, the terminations observed in $4 \mathrm{C} \beta$ are more consistent with the notion of extreme retinotopic specificity than those in $4 \mathrm{C} \alpha$.

In light of these observations, it is tempting to conclude that Hubel et al. (1974), who did not distinguish between the upper and the lower parts of layer $4 \mathrm{C}$, in fact recorded from the lower, $\beta$, subdivision. Bullier and Henry (1980), for example, report that there are relatively few nonoriented cells in $4 \mathrm{C} \alpha$ and that, in terms of receptive field organization, there is little difference between $4 \mathrm{C} \alpha$ and 4B. Work from our own laboratory, however, confirms the earlier observations of Hubel et al. (1974) for all of $4 \mathrm{C} \beta$ and certainly for the lower half of $4 \mathrm{C} \alpha$ (Blasdel and Lund, 1982b). Although the most dramatic differences between the nonoriented cells of $4 \mathrm{C} \alpha$ and $4 \mathrm{C} \beta$ are to be found in contrast sensitivity and receptive field center size, there may be a small difference in the amount of positional scatter as well. Small amounts of scatter are difficult to document, however, and it remains to be determined if they can be correlated with the 6-fold differences that are seen in the territories occupied by individual afferents to the two subdivisions of layer $4 \mathrm{C}$. In any case, a map of nonoriented units exits in $4 \mathrm{C} \alpha$ and its dimensions are such that it can be discerned within the width of a single ocular dominance column. This map, therefore, has the additional interesting distinction of being discernible within the dimensions of a single afferent arbor. The mechanisms that can account for this are unknown but might be presumed to include some form of intrinsic processing that supplements the topographical order laid down by incoming fibers. The need for such a mechanism has been suggested previously, by Barlow (1981), as an explanation for psychophysical phenomena such as hyperacuity and the elimination of motion blur.

\section{References}

Adams, J. C. (1981) Heavy metal intensification of DAB-based HRP reaction product. J. Histochem. Cytochem. 29: 775.

Barlow, H. B. (1981) Critical limiting factors in the design of the eye and visual cortex. Proc. R. Soc. Lond. Biol. 212: 1-34. Benevento, L. A., M. Rezak, and J. Bos (1975) Extrageniculate 
projections to layers VI and I of striate cortex (area 17) in the rhesus monkey (Macaca mulatta). Brain Res. 96: 51-55.

Blasdel, G. G., and J. S. Lund (1982a) Specific patterns of arborization of physiologically identified axons in macaque striate cortex. Invest. Ophthalmol. Vis. Sci. 22: 11.

Blasdel, G. G., and J. S. Lund (1982b) Physiological and morphological analysis of afferent axons in thalamo-recipient laminae of macaque striate cortex. Soc. Neurosci. Abst. 8: 705.

Blasdel, G. G., S. L. Mates, and J. S. Lund (1981) Afferent axon arborisations in layer $4 \mathrm{C}$ of macaque striate cortex. ARVO abstract. Invest. Ophthalmol. Vis. Sci. 20: 175.

Bowling, D. B., and C. R. Michael (1980) Projection patterns of single physiologically characterized optic tract fibres in cat. Nature 286: 899-902.

Bullier, J., and G. H. Henry (1980) Ordinal position of afferent input of neurons in monkey striate cortex. J. Comp. Neurol. 193: 913-936.

Carey, R. G., M. F. Bear, and I. T. Diamond (1980) The laminar organization of the reciprocal projections between the claustrum and striate cortex in the tree shrew, Tupaia glis. Brain Res. 184: 193-198.

Chow, K. L., J. S. Blum, and R. A. Blum (1950) Cell ratios in the thalamo-cortical visual system of Macaca mulatta. J. Comp. Neurol. 92: 227-239.

Dreher, B., Y. Fukuda, and R. W. Rodieck (1976) Identification, classification and anatomical segregation of cells with $\mathrm{X}$-like and Y-like properties in the lateral geniculate nucleus of oldworld primates. J. Physiol. (Lond.) 258: 433-452.

Feldberg, W., and K. Fleischauer (1960) Penetration of bromophenol blue from the perfused cerebral ventricals into the brain tissue. J. Physiol. (Lond.) 150: 451-462.

Ferster, D., and S. LeVay (1978) The axonal arborizations of lateral geniculate neurons in the striate cortex of the cat. J. Comp. Neurol. 182: 923-944.

Fitzpatrick, D., K. Itoh, and I. T. Diamond. (1983) The laminar organization of the lateral geniculate body and the striate cortex in the squirrel monkey (Saimiri sciureus). J. Neurosci. 3: 673-702.

Gilbert, C. D., and T. N. Wiesel (1979) Morphology and intracortical projections of functionally characterized neurones in cat visual cortex. Nature 280: 120-125.

Gouras, P. (1974) Opponent-colour cells in different layers of foveal striate cortex. J. Physiol. (Lond.) 238: 583-602.

Gray, E. G. (1959) Axo-somatic and axo-dendritic synapses of the cerebral cortex: An electron microscopic study. J. Anat. 93: 420-433.

Hendrickson, A. E., J. R. Wilson, and M. P. Ogren (1978) The neuroanatomical organizations of pathways between dorsal lateral geniculate nucleus and visual cortex in old and new world primates. J. Comp. Neurol. 182: 123-136.

Hubel, D. H., and D. C. Freeman (1977) Projection into the visual field of ocular dominance columns in macaque monkey. Brain Res. 122: 336-343.

Hubel, D. H., and M. S. Livingston (1981) Regions of poor orientation tuning coincide with patches of cytochrome oxidase staining in monkey striate cortex. Soc. Neurosci. Abstr. 7: 357.

Hubel, D. H., and T. N. Wiesel (1968) Receptive fields and functional architecture of monkey striate cortex. J. Physiol. (Lond.) 195: 215-243.

Hubel, D. H., and T. N. Wiesel (1972) Laminar and colummar distribution of geniculo-cortical fibers in the macaque monkey. J. Comp. Neurol. 146: 421-450.

Hubel, D. H., and T. N. Wiesel (1974) Uniformity of monkey striate cortex: A parallel relationship between field size, scatter and magnification factor. J. Comp. Neurol, 158: 295-306.

Hubel, D. H., and T. N. Wiesel (1977) Functional architecture of macaque monkey visual cortex. Proc. R. Soc. Lond. Biol. 198: 1-59.

Hubel, D. H., T. N. Wiesel, and S. LeVay (1974) Visual field of representation in layer IVc of monkey striate cortex. In Society for Neuroscience Program and Abstracts (4th Annual Meeting), p. 264.

Hubel, D. H., T. N. Wiesel, and S. LeVay (1977) Plasticity of ocular dominance columns in monkey striate cortex. Philos. Trans. R. Soc. Lond. (Biol.) 278: 377-409.

Lee, B. B., O. D. Creutzfeldt, and A. Elepfandt (1979) The responses of magno- and parvocellular cells of the monkey's lateral geniculate body to moving stimuli. Exp. Brain Res. 35: 547-557.

Lennie, P., and A. Derrington (1981) Spatial contrast sensitivity in the macaque's LGN. Invest. Ophthalmol. Vis. Sci. 20: 20.

LeVay, S., and H. A. Sherk (1981) The visual claustrum of the cat. I. Structure and connections. J. Neurosci. 1: 956-980.

LeVay, S., D. H. Hubel, and T. N. Wiesel (1975) The pattern of ocular dominance columns in macaque visual cortex revealed by a reduced silver stain. J. Comp. Neurol. 159: 559-576.

LeVay, S., T. N. Wiesel, and D. H. Hubel (1980) The development of ocular dominance columns in normal and visually deprived monkeys. J. Comp. Neurol. 191: 1-51.

Lund, J. S. (1973) Organization of neurons in the visual cortex, area 17, of the monkey (Macaca mulatta). J. Comp. Neurol. 147: 455-496.

Lund, J. S. (1980) Intrinsic organization of the primate visual cortex, area 17, as seen in Golgi preparations. In The Organization of the Cerebral Cortex, Proceedings of a Neuroscience Research Program Colloquium, F. O. Schmitt, F. G. Worden, G. Adelman, and S. G. Dennis, eds., pp. 105-124, MIT Press, Cambridge, MA.

Lund, J. S., and R. G. Boothe (1975) Interlaminar connections and pyramidal neuron organization in the visual cortex, area 17, of the macaque monkey. J. Comp. Neurol. 159: 305-334.

Lund, J. S., R. G. Boothe, and R. D. Lund (1977) Development of neurons in the visual cortex (area 17) of the monkey (Macaca nemestrina): A Golgi study from fetal day 127 to postnatal maturity. J. Comp. Neurol. 176: 149-188.

Marrocco, R. T., J. W. McClurkin, and R. A. Young (1982) Spatial summation and conduction latency classification of cells of the lateral geniculate nucleus of macaques. J. Neurosci. 2: 1275-1291.

Michacl, C. R. (1978) Color vision mechanisms in monkey striate cortex: Dual-opponent cells with concentric receptive fields. J. Neurophysiol 41: 572-588.

Ogren, M. P., and A. E. Hendrickson (1976) Pathways between striate cortex and subcortical regions in Macaca mulatta and Saimiri sciureus: Evidence for reciprocal pulvinar connection. Exp. Neurol. 53: 780-800.

Rakic, P. (1977) Prenatal development of the visual system in the rhesus monkey. Philos. Trans. R. Soc. Lond. (Biol.) 278: $245-260$.

Rockland, K. S., and D. N. Pandya (1981) Cortical connections of the occipital cortex in the rhesus monkey: Interconnections between areas 17, 18, 19 and the superior temporal sulcus. Brain Res. 212: 249-270.

Schiller, P. H., and J. G. Malpeli (1978) Functional specificity of lateral geniculate nucleus laminae of the rhesus monkey. J. Neurophysiol. 41: 788-797.

Shapley, R., E. Kaplan, and R. Soodak (1981) Spatial summation and contrast sensitivity of $\mathrm{X}$ and $\mathrm{Y}$ cells in the lateral geniculate nucleus of the macaque. Nature 292: 543-545.

Sherman, S. M., J. R. Wilson, J. H. Kaas, and S. V. Webb (1976) X-and Y-cells in the dorsal lateral geniculate nucleus of the owl monkey (Aotus trivirgatus). Science 192: 475-477.

Spatz, W. B. (1977) Topographically organized reciprocal connections between areas 17 and MT (visual area of superior 
temporal sulcus) in the marmoset Callithrix jacchus. Exp. Brain Res. 27: 559-572.

Sur, M., and S. M. Sherman (1982) Retinogeniculate terminations in cats: Morphological differences between X and Y cell axons. Science 218: 389-391.

Tigges, J., M. Tigges, and A. A. Perrachio (1977) Complementary laminar terminations of afferents to area 17 originating in area 18 and in the lateral geniculate nucleus in squirrel monkey (Saimiri). J. Comp. Neurol. 176: 87-100.

Tigges, J., M. Tigges, N. A. Cross, R. L. McBride, W. D. Letbetter, and S. Anschel (1982) Subcortical structures projecting to visual cortical areas in squirrel monkey. J. Comp. Neurol. 209: 29-40.
Valverde, F. (1971) Short axon neuronal subsystems in the visual cortex of the monkey. Int. J. Neurosci. 1: 181-197.

Wiesel, T. N., and D. H. Hubel (1966) Spatial and chromatic interactions in the lateral geniculate body of the rhesus monkey. J. Neurophysiol. 29: 1115-1156.

Winficld, D. A., M. Rivera-Dominguez, and T. P. S. Powell (1981) The termination of geniculocortical fibres in area 17 of the visual cortex in the macaque monkey. Brain Res. 231: 19-32.

Wolbarsht, M. L., E. F. MacNichol, and H. G. Wagner (1960) Glass insulated platinum microelectrode. Science 132: 13091310 . 